\title{
Multi-Frequency Inversion of Ps and Sp Receiver Functions: Methodology and Application to USArray Data
}

\author{
Felix Bissig ${ }^{1}$, Amir Khan ${ }^{1,2}$, Benoit Tauzin ${ }^{3,4}$, Paolo A. Sossi ${ }^{5}$, Federico \\ D. Munch $^{6}$, Domenico Giardini ${ }^{1}$ \\ ${ }^{1}$ Institute of Geophysics, ETHZ, Zürich, Switzerland \\ ${ }^{2}$ Institute of Theoretical Physics, University of Zürich, Zürich, Switzerland \\ ${ }^{3}$ Research School of Earth Sciences, ANU, Canberra, Australia \\ ${ }^{4}$ Université de Lyon, Université Claude Bernard Lyon 1, ENS, CNRS, Laboratoire de Géologie de Lyon: \\ Terre, Planètes, Environnement, Villeurbanne, France \\ ${ }^{5}$ Institute of Geochemistry and Petrology, ETHZ, Zürich, Switzerland \\ ${ }^{6}$ Department of Earth and Planetary Science, University of California, Berkeley, USA
}

\section{Key Points:}

- We describe a method for inverting multi-frequency P-to-s and S-to-p receiver functions for mantle thermo-chemical structure

- We distinguish tectonic regions based on thermo-chemical characteristics across the USA from the active West to the cratonic-orogenic East

- We observe strong thermo-chemically induced and interrelated topographic variations of the lithospheric base and the 410-km discontinuity 


\begin{abstract}
We image the thermo-chemical structure of crust and mantle underneath the North American continent by inverting recordings of P-to-s (Ps) and S-to-p (Sp) converted seismic body waves (receiver functions; RF). Through careful data selection and processing, we construct a multi-frequency Ps $(5,8,10 \mathrm{~s})$ and Sp $(10,15 \mathrm{~s}) \mathrm{RF}$ data set from USArray recordings. The inversion is interfaced with petrological phase equilibria computations to build self-consistent radial seismic velocity and density models for RF waveform simulations. Inverted models are combined through back-projection along converted raypaths and interpolation to tomographic images of crust and mantle structure. Through clustering analysis we identify three major tectonic regions based on mantle thermo-chemical and seismic structure: the tectonically active West (TAW), the central transition regions (CTR), and the cratonic-orogenic East (COE). TAW is chemically more fertile with a $\mathrm{Mg} \# \sim 0.90$ (molar $\mathrm{Mg} \#=\mathrm{Mg} / \mathrm{Mg}+\mathrm{Fe}$ ) and an elevated mantle potential temperature of $1490 \pm 27^{\circ} \mathrm{C}$ relative to $\mathrm{COE}$, which is chemically more depleted $(\mathrm{Mg} \# \sim 0.91)$ and colder $\left(1419 \pm 27^{\circ} \mathrm{C}\right)$. CTR is intermediate to TAW and COE. We find significant thermo-chemicallyinduced topography associated with the base of the lithosphere $( \pm 90 \mathrm{~km})$, while the mantle transition zone is mostly influenced by thermally-induced topography on the 410-km discontinuity $( \pm 15 \mathrm{~km})$. In contrast, the $660-\mathrm{km}$ discontinuity, where variations are only $\pm 5 \mathrm{~km}$, reflects a more complex thermo-chemical interplay. To place the results in a tectonic context, thermobarometric estimates from basaltic rocks across the western USA are integrated with the seismic inversions to produce a thermal model of the underlying mantle.
\end{abstract}

\title{
1 Introduction
}

Earth's thermal and compositional structure is the result of wide-ranging dynamical processes that have shaped and continue to shape the planet's surface and interior. Seismology provides tools for imaging traces of these processes, such as subducting slabs, thick continental roots, and mantle plumes, through their influence on material properties and thus seismic wave velocities and propagation.

These geologic features can be seismically imaged using converted, reflected, and refracted body waves (e.g. Farra \& Vinnik, 2000; Flanagan \& Shearer, 1998; Tan \& Helmberger, 2007). For example, the construction of receiver functions (RFs) allows to extract timing and amplitude of P-to-s (Ps) and S-to-p (Sp) converted phases, which serve as proxy for imaging depth and sharpness of seismic discontinuities beneath a station, respectively (cf. Figure 1; Vinnik, 1977; Langston, 1979). Important seismic discontinuities include the base of the crust (Moho), the lithosphere-asthenosphere boundary (LAB), and the bounding discontinuities of the mantle transition zone (MTZ).

While the LAB primarily marks a change in thermal and rheological regime (e.g., Jaupart \& Mareschal, 1999; Artemieva \& Mooney, 2001; Eaton et al., 2009), two globally observable discontinuities bound the MTZ that are associated with the transformation of the mantle minerals olivine to wadsleyite and ringwoodite to bridgemanite+ferropericlase at depths of $\sim 410$ and $\sim 660 \mathrm{~km}$ depth, respectively (Ringwood, 1975; Dziewonski \& Anderson, 1981). The exact depth of these discontinuities (hereafter referred to as 410 and 660 ), is a non-linear function of local temperature, pressure, and composition (Bina \& Helffrich, 1994; G. Helffrich, 2000; Xu et al., 2008). The RF technique serves as an excellent tool to study lateral thermo-chemically induced variations in discontinuity structure (e.g. Kumar et al., 2005; Lawrence \& Shearer, 2006; Sodoudi et al., 2006; Andrews \& Deuss, 2008; Tauzin et al., 2008; Geissler et al., 2010; Vinnik et al., 2010; Cottaar \& Deuss, 2016; Knapmeyer-Endrun et al., 2017; Tauzin et al., 2017; Makushkina et al., 2019; Monna et al., 2019; Munch et al., 2020).

Here we consider Ps and Sp RFs to study crust, lithosphere, and mantle underneath the contiguous USA, which, from a geological point of view, offers a plethora of past and recent processes, encompassing areas from active tectonic regions in the west to precambrian and phanerozoic continental masses in the central and eastern parts (cf. Figure 2A- 
B, Hoffman, 1989; Williams et al., 1991; Whitmeyer \& Karlstrom, 2007; Mooney \& Kaban, 2010). Seismic studies of the North American lithosphere, its base, and intra-lithospheric discontinuities have been considered extensively and provided insights into the processes that formed these complex continental entities (e.g., Rychert et al., 2007; H. Yuan \& Romanovicz, 2010; Abt et al., 2010; H. Yuan et al., 2014; S. M. Hansen et al., 2015; Kind et al., 2015; Afonso et al., 2016; Calò et al., 2016; Eilon et al., 2018; Boyce et al., 2019; Kind et al., 2020). Seismic imaging of the mantle have tracked both recent (e.g., Juan de Fuca slab, Yellowstone plume) and ancient tectonic features (e.g., Farallon slab) (e.g., van der Lee \& Nolet, 1997; Burdick et al., 2008; Nettles \& Dziewonski, 2008; Obrebski et al., 2010; Sigloch, 2011; Porritt et al., 2014; C. Chen et al., 2015; Maguire et al., 2018; Nelson \& Grand, 2018; Krischer et al., 2018).

In this study, we aim to improve our current understanding of mantle structure and its relation to past and present dynamical processes underneath the North American continent by providing a more detailed view of the combined thermo-chemical structure of Moho, LAB, upper mantle, and MTZ. For this purpose, we will build upon and extend the work of Munch et al. (2018), who combined mineral phase equilibrium computations with geophysical inversion to self-consistently image the thermo-chemical structure of the MTZ using P-to-s waves converted at the 410 (P410s) and 660 (P660s). There are several advantages to this approach in that it anchors temperature, composition, seismic properties, and discontinuities that are in laboratory-based forward models, while simultaneously permitting, through inversion, to optimize profiles of physical properties (e.g., S-wave velocity) to match seismic data.

We consider a number of improvements and extensions to our previous work by 1 ) including Sp RFs; 2) considering multiple frequency bands for both Ps and Sp RFs; and 3) applying the methodology to USArray data to perform a tomographic study of the North American continent. Points 1) and 2) allow for significant improvement in resolution of lithosphere, upper mantle, and transition zone structure. With these improvements in place, we are able to identify three major tectonic provinces based directly on differences in mantle thermo-chemical and seismic structure that show significant thermochemically induced variations across the LAB and MTZ. We further observe well known tectonic features in our tomographic images, such as hot mantle upwelling underneath the western USA as well as traces of active and ancient subduction.

This paper is divided into two parts: a methodological and an application part. In part 1 (sections $2-3$ ), we describe seismic data processing to construct a new set of multifrequency Ps and Sp RFs using USArray data with particular emphasis on Sp RFs (Ps RFs are detailed in Munch et al. (2018)), including data selection, deconvolution, spatial sensitivity analysis, stacking and uncertainty estimation, and RF modeling as part of which we perform a benchmark of one-dimensional (1-D) synthetic waveforms against three dimensional (3-D) full waveform synthetics to validate our 1-D modeling approach to computing seismograms. In part 2 (sections 4-7), we apply the developed methodology to obtain self-consistent tomographic images of the crust, lithosphere, and mantle underneath the North American continent. Part 2 includes model parametrization, inversion procedure, and discussion of results. Finally, to further test the results presented here, we compare our thermal model with an independent model of the western USA constructed from thermobarometry data.

\section{Data processing}

The fundamental idea of the receiver function method is to separate signals generated by the direct and converted phases on three-component ground-motion recordings based on their distinct particle motion (e.g., Rondenay, 2009; Kind et al., 2012). In the case of a P-to-s conversion, the P-motion is recorded on the vertical component and the converted wave on the radial component, while the order is reversed for S-to-p conversions. The converted signal can be considered as the convolution of the direct wavefield with the local structural response. Thus, deconvolving the "source"- (i.e., direct phase) 
from the "response"-trace (i.e., converted phase) results in a time series representing the structure below the receiver. This time series is called the receiver function (cf. Figure 1BC; Vinnik, 1977; Langston, 1979). Source and path effects between event and conversion point are assumed to be removed through the deconvolution operation, as all this information is contained in both, source- and response-traces (Kind et al., 2012).

In spite of certain advantages of Sp over Ps RFs, the use of the former for making structural inferences is limited relative to the latter because of limitations that beset S-waves (e.g., Bock, 1994; Farra \& Vinnik, 2000; X. Yuan et al., 2006; Wilson et al., 2006). Firstly, the incidence angle of S-to-p converted phases is larger than that of the original S-wave, causing post-critical incidence to restrict the usage of Sp RFs to narrower epicentral distance ranges and depths shallower than $660 \mathrm{~km}$ (cf. Figure 1A). Also, because of the large incidence angle, S-to-p conversion points are located farther away from the station than in the case of P-to-s, which ultimately results in broader regional sampling. Added to this, is a lower spatial resolution because of a lower frequency content of S-waves relative to P-waves. Secondly, the signal-to-noise ratio (SNR) of S-waves is lower than for P-waves because of a range of interfering phases, which generally complicates observation of S-to-p converted phases. In this context, Bock (1994) and Wilson et al. (2006) have pointed out that amplitudes of P-wave multiples between the surface and the MTZ can become significant to the extent that these can be mistaken for conversions. Thirdly, core-phases (ScS, SKS, and their respective conversions) in the epicentral distance range $\sim 85^{\circ}-100^{\circ}$ interfere with S-to-p conversions, in particular S660p phases (X. Yuan et al., 2006). These issues can, however, to a large extent be mitigated through careful data selection and processing steps as described in e.g., Wilson et al. (2006); Monna et al. (2019); X. Shen et al. (2019).

\subsection{Data selection}

We collected and processed data recorded at stations of the USArray (Figure 2C), which includes about 100 reference stations in complementary use to the denser transportable network. Seismic data were acquired from the IRIS datacenter (Incorporated Research Institutions for Seismology, ds.iris.edu/ds/nodes/dmc/) using ObspyDMT (Hosseini \& Sigloch, 2017). Event selection is based on information available from the global centroid moment tensor catalogue (Dziewonski et al., 1981; Ekström et al., 2012, www.globalcmt.org). Only events with a magnitude of at least 5.5 and a focal depth shallower than $150 \mathrm{~km}$ were selected. The latter criterion is applied to reduce the interference of S-to-p conversions with surface-reflected multiples (Wilson et al., 2006). For constructing Ps RFs, we select events in the epicentral distance $(\Delta)$ range $40^{\circ}-95^{\circ}$ (e.g., Andrews \& Deuss, 2008). For Sp RFs, we are restricted to a $\Delta$ range of $55^{\circ}-90^{\circ}$ because of post-critical incidence. Also, because of the simultaneous arrival of SKS and ScS (including their conversions) beyond $85^{\circ}$, the S660p conversion is very difficult to observe (X. Yuan et al., 2006). We therefore focus on S-to-p conversions at discontinuities between the Moho and the 410. The selected distance ranges and the respective travel times of direct and converted waves are shown in supplementary Figure S.1.

\subsection{Receiver function processing}

For each event, recordings are filtered between $0.02 \mathrm{~Hz}$ and $1 \mathrm{~Hz}$ using a Butterworth bandpass filter of $2^{\text {nd }}$ order and then rotated to the ZRT (vertical-radial-transverse) system under consideration of the back-azimuth computed from the source and receiver locations. In the Sp case, we additionally rotate waveforms to the LQT-system, where the orthogonal L and Q components are approximately aligned with the S and S-to-p converted phases, respectively, improving their detectability (Rondenay, 2009; Kind et al., 2012). The orientation of the L- and Q-axes is determined by maximizing the energy in the window from $-30 \mathrm{~s}$ to $+50 \mathrm{~s}$ on the Z-/L-component around the theoretical $\mathrm{S}$-wave arrival by means of principal component analysis (PCA; see supplementary Fig- 
ure S.2). In order to determine the SNR and exact arrival of the direct phase, we implemented the automated picking approach of Abt et al. (2010). An illustration hereof is shown in supplementary Figure S.3. To ensure high-quality data, we only consider waveforms with a SNR $>5$. Alternative SNR criteria for detecting lithospheric S-to-p conversions have also been proposed by X. Shen et al. (2019) and Monna et al. (2019).

\subsubsection{Deconvolution}

Receiver functions are obtained from deconvolving source (direct phase) from response waveform (converted phase). The source wavelet is extracted by trimming the corresponding trace around the picked arrival of the direct phase within windows from $-50 \mathrm{~s}$ to $+150 \mathrm{~s}$ and from $-100 \mathrm{~s}$ to $+30 \mathrm{~s}$ for Ps and Sp RFs, respectively. Analogously, the response trace is cut within a window from $-50 \mathrm{~s}$ to $+150 \mathrm{~s}$ and from $-150 \mathrm{~s}$ to $+50 \mathrm{~s}$ for Ps and Sp RFs, respectively. The tapered source and response waveforms are subsequently deconvolved using iterative time-domain deconvolution (Ligorría \& Ammon, 1999). For removing high-frequency noise from the RFs, a Butterworth lowpass filter of $2^{\text {nd }}$ order is applied for different corner periods: $5 \mathrm{~s}, 8 \mathrm{~s}$, and $10 \mathrm{~s}$ for Ps RFs and $10 \mathrm{~s}$ and $15 \mathrm{~s}$ for Sp RFs. This choice is dictated by the increased noise-content at shorter periods and lack of resolution at longer periods, respectively. Maximum wavelengths associated with these periods are 28-56 km for Ps and 90-135 km for Sp RFs, respectively. Since the arrival times of converted phases not only depend on the structure below the receiver but also on the slowness of the ray, we stretch and compress the time axis of each $\mathrm{RF}$ to a reference slowness (moveout correction), that is $6.5 \mathrm{~s} /{ }^{\circ}$ for Ps RFs and $9.9 \mathrm{~s} /{ }^{\circ}$ for Sp RFs. For comparison with Ps RFs, the time axis and polarity of Sp RFs are flipped.

\subsubsection{Stacking and uncertainty estimate}

To further enhance SNR, we stack individual RF traces at a given station. This ensures that information from many events, where focal depth, mechanism, and epicentral distance differ, are combined coherently. Phases not aligned through the moveout correction are cancelled and hence direct conversions enhanced. To determine uncertainties on RFs, we employ a bootstrap resampling approach (Efron \& Tibshirani, 1991) and compute the standard deviation of 100 stacks, where each stack is formed from $n$ randomly recombined RFs, with $n$ being the number of available RF traces. A crucial choice has to be made on the selection of RF traces to be included in a stack, as this depends on the spatial sensitivity of the data set, i.e., location of conversion points relative to station and frequency content.

\subsubsection{Spatial sensitivity of Sp RFs}

Assuming the main sensitivity of a RF to be confined to the region directly beneath the station allows us to sum all moveout-corrected RF traces available to form a stack. While this assumption is reasonable for P-to-s conversions and therefore applied to the Ps RF data set, it is not directly applicable to the S-to-p conversions, because of the high incidence angles compared to the direct S-wave. Consequently, S-to-p conversion points are located significantly further away from the station than those of P-to-s converted waves from the same depth (cf. Figure 1A). Moreover, S-to-p converted waves propagate faster and hence have longer wavelengths. These effects are illustrated for Sp RFs obtained at station 39-COWI ('39' referring to the station-ID in Figure 2C and 'COWI' being the station-abbreviation) and filtered at $10 \mathrm{~s}$ period by computing and plotting the Fresnel volumes of converted waves at different depth slices following the approaches of Lekić et al. (2011) and Cottaar and Deuss (2016). For each event present in the Sp RF data set for station 39-COWI, we 1) determine S-to-p conversion points at depth Z using raytracing through IASP91 (Kennett \& Engdahl, 1991; Crotwell et al., 1999), and 2) compute the Fresnel zone half-width, $\delta^{\mathrm{HW}}$, at the same depth $\mathrm{Z}$, which is a function of wave- 
length, $\lambda$, via:

$$
\delta^{\mathrm{HW}}=\sqrt{\left(\frac{\lambda}{3}+\mathrm{Z}\right)^{2}-\mathrm{Z}^{2}}
$$

where $\lambda$ is obtained by multiplying the P-wave velocity above Z, i.e., the velocity of the converted wave, with the dominant period (here $10 \mathrm{~s}$ ). Knowing the location of conversion points and Fresnel zones, we evaluate the lateral sensitivity of the ray by comparing $\delta^{\mathrm{HW}}$ for each node on a discrete grid at distance $\delta$ to the conversion point of interest via normalized cubic splines:

$$
\mathrm{W}= \begin{cases}\frac{3}{4} \bar{\delta}^{3}-\frac{3}{2} \bar{\delta}^{2}+1, & \text { if } \bar{\delta} \leq 1 \\ \frac{1}{4}(2-\bar{\delta})^{3}, & \text { if } 1<\bar{\delta} \leq 2 \\ 0, & \text { if } \bar{\delta} \geq 2\end{cases}
$$

where $\bar{\delta}=\delta / \delta^{\mathrm{HW}}$. We performed this analysis for conversions at $210 \mathrm{~km}$ and $410 \mathrm{~km}$ depth (see Figure $3 \mathrm{~A}-\mathrm{B}$ ). The weights of all rays included in a certain back-azimuth bin are summed and re-scaled by the maximum value to facilitate comparison. Note that the width of the Fresnel volume is not the resolution limit of a seismic wave (Spetzler \& Snieder, 2004), but serves as a useful illustration of the latter.

For station 39-COWI, we observe that the group of events emanating from the western Pacific, South America, and Europe (Figure 3E) produce distinct sensitivity clusters at $210 \mathrm{~km}$ and $410 \mathrm{~km}$ depth (Figure 3A-B). Their clear separation indicates that summing RFs from the entire data set would lead to averaging of lithospheric and upper mantle structure from different regions. Instead, it requires forming stacks that are sorted by back-azimuth (e.g., Vinnik et al., 2005; Vinnik et al., 2010; Monna et al., 2019). However, back-azimuth binned stacks reduce the number of useful traces available in one back-azimuth bin to between 10 and 80; yet, Sp RF stacks containing less than $\sim 100$ traces tend to be noisy and, consequently, less robust (see supplementary section S.2). A possible work-around is to increase the number of traces within a back-azimuth bin by incorporating additional data as shown in the following.

\subsubsection{Back-azimuth stacking using additional stations}

In addition to the reference network (Figure 2C), USArray also consists of a dense network of transportable stations. Since stations are only spaced about $60 \mathrm{~km}$ apart, events of similar back-azimuth recorded at neighbouring stations will produce S-to-p converted waves that sample a similar region as illustrated in Figure $3 \mathrm{C}-\mathrm{D}$. Thus, the amount of data in a back-azimuth bin for a given reference station can be increased by including data recorded at near-by transportable stations.

This is illustrated in Figure 4 for the reference station 39-COWI, which shows how the uncertainty and amplitudes of the Sp RF stack evolve as traces from the transportable stations closest to 39-COWI are added for events in the western Pacific (back-azimuth bin \#1, panels A and B) and Europe (back-azimuth bin \#3, panels C and D), respectively. For both back-azimuth clusters, we see that the bootstrap-derived mean uncertainty of the cumulative stack decreases and that RF amplitudes change when the number of traces is increased. The improvement in the quality of the Sp RF is particularly evident in the case of the S410p phase that emerges in back-azimuth bin \#3, which is far less apparent in the Sp RF 39-COWI-only stack. Although the final number of traces used $(\sim 50)$ for this particular event cluster remains below the threshold associated with a robust stack, back-azimuth bin \#1 includes more than 150 traces. In combination with the clear signals emanating from Moho, lithosphere, and the 410-km discontinuity, we therefore consider this to be a high-quality stack and retain it for the inversion.

An alternative approach would be common-conversion point (CCP) stacking, which migrates each individual RF trace from time- to depth-domain according to its conversion points (e.g., Dueker \& Sheehan, 1997; Kosarev et al., 1999; Rondenay, 2009; Lekić et al., 2011; Lekić \& Fischer, 2014; Cottaar \& Deuss, 2016; Lekić \& Fischer, 2017; Kind 
et al., 2020). This method, however, depends crucially on the background velocity model used for migration and, unless data are properly re-processed during inversion using the currently updated velocity model, is not self-consistent and therefore limited in accuracy.

\subsection{Data workflow summary}

We processed Ps and Sp RFs for all USArray reference stations (Figure 2C). This included the following steps:

- Construction of a multi-frequency Ps (5, 8, and $10 \mathrm{~s}$ low-pass period) and Sp (10 and 15 s low-pass period) RF data set.

- Formation of Sp RF stacks sorted by back-azimuth by combining data recorded at USArray reference and transportable stations that are located at a maximum distance of $140 \mathrm{~km}$ from the former.

- Selection of robust and only highest quality Ps and Sp RFs with clear signals emanating from the Moho, lithosphere, 410, and 660 for the inversion (cf. Table S.1 in the supplementary material).

\section{Synthetic receiver function modeling}

In order to generate a synthetic RF stack equivalent of the observed RF stack, we first compute waveforms using the reflectivity method (Fuchs \& Müller, 1971; Müller, 1985). In order to ensure consistency, synthetic waveforms are processed the same way as the observed data (Munch et al., 2018). For optimal radiation of P and SV waves, we model the source as an explosion for Ps RFs and a normal-fault mechanism for Sp RFs. The source-time function is a Heaviside function and the modeled focal depth is imposed by the median of the depth distribution of the observed events. As the amplitudes of converted waves depend on slowness, their relative contribution to the final RF stack has to be mimicked in the synthetic RF modeling. The distribution of receivers and their relative weights in the stack therefore follows that of the distribution of the theoretical slownesses of the direct phase as imposed by the data set (Munch et al., 2018).

We exclude the uppermost layer of the model from the reflecting zone when computing waveforms for Sp RF (cf. supplementary Figure S.6). This suppresses multiple surface reflections which otherwise would constructively interfere and bias the RF. This approach is similar to the one by X. Yuan et al. (2006), who argue that propagation of multiples in a laterally heterogeneous Earth is ineffective. Ultimately, synthetic waveforms also have to conform to the following criteria: 1) the L- and Q-axis as imposed by the data set are employed to ensure consistency between observed and synthetic LQTsystems, since these affect RF amplitudes, and 2) the arrival time of the direct phase for the underlying model is determined via ray tracing (Crotwell et al., 1999), since the automated picking algorithm is unable to distinguish core phases from S-waves for $\Delta>$ $85^{\circ}$.

Finally, in order to validate our one dimensional (1-D) modeling approach to computing synthetic seismograms, we benchmarked the modeled receiver functions against three dimensional (3-D) full waveform synthetics (see supplementary section S.3.2). For this purpose, we employed the spectral element based software package Salvus (Afanasiev et al., 2019) to compute full waveforms in a 3-D velocity model. Comparison of 1-D and 3-D receiver functions is shown in supplementary Figure S.7 and the modeled waveforms are seen to be in good agreement. On the basis of this benchmark, the 1-D approach pursued here appears to be reliable for modeling both, Ps and Sp RFs, and, from a practical viewpoint, computationally much more efficient (1-D: $~ 15-20$ sec on a normal desktopcomputer, 3-D: $\sim 25$ nodehours on a supercomputer). 


\section{Model parametrization}

\subsection{Petrological model}

Building on previous experience (e.g., Khan et al., 2009; Munch et al., 2018), we model mantle composition by the weight fraction of basalt in a basalt-harzburgite mixture. This compositional model is based on the recognition that basaltic crust is generated at ridges through partial melting, leaving behind the depleted complement harzburgite (Xu et al., 2008). At subduction zones, this physically and chemically stratified oceanic lithosphere is continuously being recycled back into the mantle, where it remixes (e.g., G. R. Helffrich \& Wood, 2001; Tackley et al., 2005). The resultant mineralogy depends on the degree of equilibration between basalt and harzburgite and two mixing models have been proposed (Xu et al., 2008): equilibrium assemblage (EA) and mechanixal mixture (MM). The EA model assumes full equilibration, whereas in the MM model the mantle is a mixture of the end-members. Here, we focus on the EA model as Munch et al. (2018) have shown that RFs are less sensitive to differences between MM and EA.

For a given basalt fraction $f$, mantle composition $\mathbf{X}$ is computed from

$$
\mathbf{X}=f \mathbf{X}_{\mathrm{B}}+(1-f) \mathbf{X}_{\mathrm{H}}
$$

where $\mathbf{X}_{\mathrm{B}}$ and $\mathbf{X}_{\mathrm{H}}$ are basaltic and harzburgitic end-member compositions, respectively. To predict the relative amount of stable minerals and their physical properties along a self-consistent mantle adiabat for harzburgite and mid-ocean ridge basalt (MORB) bulk chemical compositions in the $\mathrm{Na}_{2} \mathrm{O}-\mathrm{CaO}-\mathrm{FeO}-\mathrm{MgO}-\mathrm{Al}_{2} \mathrm{O}_{3}-\mathrm{SiO}_{2}$ system (Table 1), we employ Gibbs free energy minimization and equation-of-state modeling (Perple_X; Connolly, 2009). For this purpose, we adopt the thermodynamic formulation of Stixrude and LithgowBertelloni (2005) and parameters and uncertainties as given by Stixrude and LithgowBertelloni (2011). Bulk rock properties are subsequently obtained by means of VoigtReuss-Hill averaging (Hill, 1952; Watt et al., 1976). Density and elastic moduli are accurate to within $\sim 0.5 \%$ and $\sim 1-2 \%$, respectively (Connolly \& Khan, 2016). To obtain the mantle pressure profile, we integrate the vertical load from the surface pressure boundary condition. Within the crust and lithosphere, temperature is computed by assuming a conductive geothermal gradient, while the sublithospheric mantle adiabat is defined by the entropy of the lithology at the base of the lithosphere (see supplementary Figure S.8 for an illustration).

The present thermodynamic model of Stixrude and Lithgow-Bertelloni $(2005,2011)$ has limitations: 1) the equilibrium assumption is dubious at low temperatures as equilibrium is not likely to be achieved (e.g., Wood \& Holloway, 1984). Consequently, we compute mineralogy for temperature below $500{ }^{\circ} \mathrm{C}$ at $500{ }^{\circ} \mathrm{C}$, and the resultant mineralogy is then used to calculate physical properties at the temperature of interest; and 2) the thermodynamic model does not account for redox effects (e.g., Cline II et al., 2018), minor phases, and water and melt due to lack of thermodynamic data. Both, water and melt, can significantly affect elastic properties at lithospheric and MTZ depth. Negative gradients in S-wave velocity $(>5 \%)$ at mid-lithospheric depth in continental regions could arise from hydrous minerals (D. H. Green et al., 2010; Rader et al., 2015; Selway et al., 2015) and low wave velocities at the lithosphere-asthenosphere boundary in oceanic and active regions have been attributed to partial melt (e.g., Kawakatsu et al., 2009; Rychert \& Shearer, 2009; Lekić \& Fischer, 2014; Stern et al., 2015; Clark \& Lesher, 2017; Karato \& Park, 2019). The MTZ is considered as a plausible water reservoir within the mantle given the experimentally constrained storage capacities (1-3\%) of wadsleyite and ringwoodite (Smyth, 1987; Kohlstedt et al., 1996; Férot \& Bolfan-Casanova, 2012). However, mineral physics data suggest the effect of water on seismic velocities is negligible at MTZ conditions as a result of which seismic data are insensitive to water content (Thio et al., 2015; Schulze et al., 2018). Albeit, there is geophysical evidence for regional lowvelocity layers atop the 410 (e.g., Song et al., 2004; Toffelmier \& Tyburczy, 2007; Vinnik \& Farra, 2007; Tauzin et al., 2010; Khan \& Shankland, 2012; Kind et al., 2015; Xiao 
Table 1. Model mantle compositions in wt\% of mid-ocean ridge basalt (MORB) and its depleted residue, harzburgite (from Khan et al. (2009)). $\mathrm{Mg} \#$ (molar) is given by $\mathrm{Mg} /(\mathrm{Mg}+\mathrm{Fe}$ ).

\begin{tabular}{lcc}
\hline Component & MORB, $\mathbf{X}_{\mathrm{B}}$ & Harzburgite, $\mathbf{X}_{\mathrm{H}}$ \\
\hline $\mathrm{CaO}$ & 13.05 & 0.5 \\
$\mathrm{FeO}$ & 7.68 & 7.83 \\
$\mathrm{MgO}$ & 10.49 & 46.36 \\
$\mathrm{Al}_{2} \mathrm{O}_{3}$ & 16.08 & 0.65 \\
$\mathrm{SiO}_{2}$ & 50.39 & 43.64 \\
$\mathrm{Na}_{2} \mathrm{O}$ & 1.87 & 0.01 \\
$\mathrm{Mg} \#$ & 0.709 & 0.913 \\
\hline
\end{tabular}

et al., 2020), which might be due to partial melt (Bercovici \& Karato, 2003; Hirschmann, 2006; Freitas et al., 2017). Future studies will consider this in more detail.

\subsection{Crustal structure}

The velocity structure of the crust is important for modeling receiver functions (see supplementary sections S.5.1 and S.5.3.2). Here, we follow Munch et al. (2018) and model the crust as a stack of three layers of variable thickness and S-wave velocity, which is assumed to increase with depth. The ratios of density and $\mathrm{P}$-wave velocity to $\mathrm{S}$-wave velocity are constant in the crust. We invert for all of these parameters by using conversions at the Moho and P-to-s crustal reverberations.

\subsection{Anelastic effects}

In order to model the effect of anelasticity on seismic amplitudes (Liu, 2003), we follow the scheme outlined in Munch et al. (2018), which considers a laboratory-based viscoelastic dissipation model derived from grain-size-, temperature-, and pressure-sensitive viscoelastic relaxation measurements. The dissipation model based on the extended Burgers model is described in detail in Jackson and Faul (2010) and relies on laboratory experiments in the temperature range $800-1200{ }^{\circ} \mathrm{C}$ of torsional forced oscillation data within 1-1000 s period on melt-free poly-crystalline olivine grains between 3-165 $\mu \mathrm{m}$ size. Radial profiles of shear attenuation, $\mathrm{Q}_{\mu}$, are determined for the viscoelastic extended Burgers model using the implementation of Bagheri et al. (2019), for which rheological parameters are listed in supplementary Table S.2.

The advantage of this particular set-up is that it allows us to account for, through the thermodynamic interface, the influence of temperature and pressure on the shear attenuation model in a self-consistent manner (e.g., Bagheri et al., 2019). Alternative viscoelastic models have also been proposed (e.g., Jackson \& Faul, 2010; Sundberg \& Cooper, 2010; Karato et al., 2015), but the relatively high-frequency Ps and Sp RFs are not sensitive enough to allow for proper discrimination (see discussion in supplementary section S.6.3). In case $\mathrm{Q}_{\mu}$ exceeds $600, \mathrm{Q}_{\mu}$ is set equal to 600 and bulk attenuation, $\mathrm{Q}_{\kappa}$, is held fixed at 57823 after PREM (Dziewonski \& Anderson, 1981).

\section{Inverse problem}

\subsection{Formulation of the inverse problem}

Within the Bayesian framework, the solution to the inverse problem $\mathbf{d}=\mathrm{g}(\mathbf{m})$, where $\mathbf{d}$ is a data vector containing observations and $g$ a typically non-linear operator 
Table 2. Overview of model parameters, their quantity, and prior model parameter ranges and probability distributions

\begin{tabular}{|c|c|c|c|c|}
\hline Description & Parameter & Quantity & Value/range & Distribution \\
\hline Basalt fraction & $f$ & 1 & $0-0.5$ & uniform \\
\hline Lithospheric temperature $\left({ }^{\circ} \mathrm{C}\right)$ & $\mathrm{T}_{\text {lit }}$ & 1 & $950-1600$ & uniform \\
\hline Lithospheric thickness (km) & $\mathrm{Z}_{\text {lit }}$ & 1 & $70-300$ & uniform \\
\hline Crustal layer thicknesses (km) & $\delta \mathrm{Z}$ & 3 & $1-20$ & uniform \\
\hline $\begin{array}{l}\text { S-wave velocity of uppermost } \\
\text { crustal layer }(\mathrm{km} / \mathrm{s})\end{array}$ & $\mathrm{V}_{\mathrm{S}}^{1}$ & 1 & $2.0-4.1$ & uniform \\
\hline $\begin{array}{l}\text { S-wave velocity change across } \\
\text { crustal discontinuities }(\mathrm{km} / \mathrm{s})\end{array}$ & $\delta \mathrm{V}_{\mathrm{S}}$ & 2 & $0-0.5$ & uniform \\
\hline Density- and P-to-S-wave & $\rho / \mathrm{V}_{\mathrm{S}}$ & 1 & $0.768 \pm 0.0213$ & normal \\
\hline velocity crustal ratios & $\mathrm{V}_{\mathrm{P}} / \mathrm{V}_{\mathrm{S}}$ & 1 & $1.746 \pm 0.0195$ & normal \\
\hline
\end{tabular}

that maps a model parameter vector $\mathbf{m}$ into data, is given by (Mosegaard \& Tarantola, 1995)

$$
\sigma(\mathbf{d}, \mathbf{m})=k \cdot h(\mathbf{m}) \mathcal{L}(\mathbf{d}, \mathbf{m}),
$$

\subsection{Sampling of the posterior}

We sample the posterior distribution by means of the Metropolis-Hastings algorithm (Metropolis et al., 1953; Hastings, 1970). This algorithm is based on random sam-

where

$$
\Phi_{\mathrm{T}, \mathrm{i}}^{\mathrm{RF}}=\frac{1}{\mathrm{~N}} \sum_{\mathrm{j}}^{\mathrm{N}} \frac{\left\|\mathbf{d}_{\mathrm{j}}^{\text {obs }}-\mathbf{d}_{\mathrm{j}}^{\mathrm{syn}}\right\|^{2}}{2 \sigma_{\mathrm{j}}^{2}}
$$

with $\mathbf{d}_{\mathbf{j}}^{\text {obs }}, \mathbf{d}_{\mathbf{j}}^{\text {syn }}$, and $\sigma_{\mathrm{j}}$ being synthetic and observed Ps or Sp RF amplitudes (for a given period and window) and data uncertainty of data point $\mathrm{j}$, respectively, with $\mathrm{N}$ denoting the total number of points within each misfit window. Consequently, the total likelihood function for a given station, RF-type, and back-azimuth bin is the conjunction of the likelihood functions associated with each period and misfit window:

$$
\mathcal{L}(\mathbf{d}, \mathbf{m})=\prod_{\mathrm{T}, \mathrm{i}} \mathcal{L}_{\mathrm{T}, \mathrm{i}}^{\mathrm{RF}}(\mathbf{d}, \mathbf{m})
$$


pling of the model space, yet only models that result in a good data fit and are consistent with prior information are frequently sampled (importance sampling). At each step $n$, a model, $\mathbf{m}^{n+1}$, is proposed on the basis of the prior distribution and is either accepted or rejected based on the probability

$$
P=\min \left[1, \frac{\mathcal{L}\left(\mathbf{m}^{n+1}\right)}{\mathcal{L}\left(\mathbf{m}^{n}\right)}\right],
$$

where $\mathbf{m}^{\mathrm{n}}$ represents the last accepted model. In a slight modification, we use the cascaded Metropolis algorithm (Mosegaard \& Tarantola, 1995, 2002), which applies the acceptance criterion (Eq. 8) to each period T and misfit window i (crust, lithosphere, 410, and 660) separately for a given station and individual RF-type (and back-azimuth bin):

( $\star$ propose move: $\mathbf{m}_{\mathrm{RF}}^{n} \longrightarrow \mathbf{m}_{\mathrm{RF}}^{n+1} \mathrm{RF}=\mathrm{Ps}$ or $\mathrm{RF}=\mathrm{Sp}$

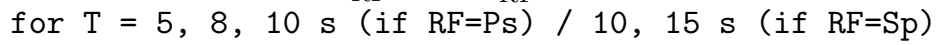

Thus, the model is only retained if all of the individual steps are accepted. This acceptance criterion is more strict when compared to the "standard" acceptance criterion of the Metropolis-Hastings algorithm, but acts to prevent trade-offs between misfit windows as these are considered separately.

Finally, to improve McMC performance, we reduced the burn-in of the sampling stage by employing a global optimisation method in order to obtain a good initial model for the subsequent model space search. For this purpose, we use the Covariance Matrix Adaption Evolution Strategy of Hansen and Ostermeier (2001). We first search for a crustal model by minimizing the misfit in the crustal time window, and subsequently refine both crustal and thermo-chemical model by minimizing misfit across all windows. In the McMC stage, we sampled $\sim 40000$ models in total by running 8 chains in parallel, of which $\sim 4000$ models are retained for analysis here. Step lengths are adjusted so that the acceptance rate is between $30-50 \%$. Synthetic test inversions and grid-search examples are described in the supplementary section S.5.

\subsection{A posteriori migration of inversion results}

We created a series of maps and cross sections to visualize the spatial variation of model parameters based on mean models. The use of mean models is justified given that the posterior probability density distributions (Figure 6) are mostly Gaussian. Maps and cross sections are produced through linear interpolation of the Ps and Sp RF-derived mean models, which were migrated to their point of sensitivity, which, in the case of Ps RFs, is approximately the location of the station and for Sp RFs is the conversion point of the $\mathrm{S} d \mathrm{p}$ phase (cf. section 2.2.3), where $d$ is the depth of sensitivity of a particular model parameter. For example, when migrating Sp RF-derived crustal and lithospheric thickness, $d$ equals either $\mathrm{Z}_{\mathrm{c}}$ or $\mathrm{Z}_{\mathrm{lit}}$, whereas in the case of temperature, $d$ is equal to $410 \mathrm{~km}$, since thermal information is primarily contained in the S410p phase (see supplementary Figure S.15).

For a given station, back-azimuth bin, and model parameter with sensitivity $d$, we compute the coordinates of the Sdp conversion points in IASP91 for all events included in that bin and average them to extract the final point of sensitivity. The so-computed Sp RF points are shown as diamonds in the maps that follow, while Ps RF points, i.e., station locations, are depicted as circles. All estimates related to discontinuity structure 
(Moho, LAB, and MTZ) have been corrected for station elevation. Finally, while the present inversion is not a tomographic inversion sensu stricto, it is an inversion for a set of (quasilocal) radial profiles of thermochemical and physical structure, which, when pieced together, result in tomographic images that are based on the a posteriori migration procedure.

\section{Results and Discussion}

\subsection{Datafit}

The fits to observed Ps and Sp RFs at 5 and 10 s period, respectively, are shown in Figure 5. Fits to Ps and Sp RFs at the other periods are summarised in supplementary Figure S.19. Conversions at the Moho, 410, and 660 discontinuities as well as lithospheric Sp RFs are seen to be captured well by the sampled models.

\subsection{Crustal thickness}

The inverted mean crustal thickness model is shown in Figure 7A. Results for $\rho / \mathrm{V}_{\mathrm{S}}$ and $V_{P} / V_{S}$ can be found in the supplementary material (Figure S.20). The abbreviations and extent of physiographic and tectonic provinces referred to hereafter are depicted in Figure 2A-B. As expected, crustal thickness estimates are better constrained from Ps than from Sp RFs (Figure 6A-B) given the higher frequency content of Ps RFs and the additional information contained in crustal reverberations. Mean Ps and Sp RF derived standard deviations are $1.6 \mathrm{~km}$ and $3.5 \mathrm{~km}$, respectively. For comparison, we are also showing the crustal thickness map based on Crust1.0 (Laske et al., 2013) in Figure 7B. Our model is in good agreement with Crust1.0, including other models (not shown; e.g., Lowry \& Peréz-Gussinyé, 2011; Levander \& Miller, 2012; Schmandt et al., 2015; W. Shen \& Ritzwoller, 2016; Buehler \& Shearer, 2017; Ma \& Lowry, 2017) which indicate that regions with relatively thin crust $(25-35 \mathrm{~km})$ are found in the western part of the USA, i.e., beneath the Columbia plateau (physiographic province P2) and the Basin and Range province (P3), as well as the passive margins of the continent in the southern and eastern parts (P10). Regions with thicker crust $(45-55 \mathrm{~km})$ are observed underneath the Wyoming craton (tectonic province T2) and Trans-Hudson orogen (T3) as well as within the precambrian building blocks towards the east (P6-P8; T4-T8) and south-west that extend into the Colorado plateau (P4).

\subsection{Tectonic regionalization}

In order to embed the results in a geological context, we first extracted radial profiles of temperature, $\mathrm{S}$-wave velocity, and shear attenuation on a $2.5^{\circ} \times 2.5^{\circ}$-grid and grouped them individually via k-means clustering according to their similarity, i.e., by minimizing the $\mathrm{L}_{2}$-distance to the mean profile of the respective cluster (MacQueen, 1967). This approach allows for identification of tectonic regions without any a priori constraints (e.g., Houser et al., 2008; Lekić \& Romanowicz, 2011; Lekić et al., 2012; Calò et al., 2016). Consistent results were found for three clusters that are shown in Figure 8. The radial profiles for each parameter show specific characteristics that determine the clustering: 1) temperature and depth of the intersection point of conductive geotherm and mantle adiabat; 2) amplitude and depth extent of upper mantle low-velocity zone; and 3) thickness of high- $\mathrm{Q}_{\mu}$ lid.

When the mean profile for each location is projected onto a map (see insets in Figure 8), a well-known trend that follows the tectonic division of the North American continent appears. In particular, we are able to distinguish the tectonically active west (encompassing physiographic provinces $\mathrm{P} 1-\mathrm{P} 5$ ), which is characterised by being relatively hot, of slow shear-wave velocity, and highly dissipative (red dots), from the colder, faster, and less dissipative older eastern parts (blue dots) that include the cratonic core and the 
Table 3. Summary of thermo-chemical characteristics and discontinuity structure of the main tectonic regions identified through cluster analysis in Figure 8A. Parameters are: crustal thickness $\left(\mathrm{Z}_{\mathrm{c}}\right)$, potential temperature $\left(\mathrm{T}_{\text {pot }}\right)$, lithosphere thickness $\left(\mathrm{Z}_{\mathrm{lit}}\right)$, basalt fraction $(f), \mathrm{Mg} \#$ (molar $\mathrm{Mg} /(\mathrm{Mg}+\mathrm{Fe}))$, and depth to $410\left(\mathrm{Z}_{410}\right)$ and $660\left(\mathrm{Z}_{660}\right)$. Values represent the mean and standard deviation based on the distributions shown in Figures 9C,E and 12B,D.

\begin{tabular}{llll}
\hline \multirow{2}{*}{ Parameter } & \multicolumn{3}{c}{ Tectonic region } \\
\cline { 2 - 4 } & $\begin{array}{l}\text { TAW } \\
\text { (tectonically active West) }\end{array}$ & $\begin{array}{l}\text { CTR } \\
\text { (central transition regions) }\end{array}$ & $\begin{array}{l}\text { COE } \\
\text { (cratonic-orogenic East) }\end{array}$ \\
\hline $\mathrm{Z}_{\mathrm{c}}$ & $40 \pm 5 \mathrm{~km}$ & $44 \pm 5 \mathrm{~km}$ & $44 \pm 4 \mathrm{~km}$ \\
$\mathrm{~T}_{\text {pot }}$ & $1490 \pm 27^{\circ} \mathrm{C}$ & $1429 \pm 37^{\circ} \mathrm{C}$ & $1413 \pm 27^{\circ} \mathrm{C}$ \\
$\mathrm{Z}_{\mathrm{lit}}$ & $100 \pm 23 \mathrm{~km}$ & $146 \pm 31 \mathrm{~km}$ & $208 \pm 33 \mathrm{~km}$ \\
$f$ & $13 \pm 4.5 \%$ & $11 \pm 3.0 \%$ & $10 \pm 3.6 \%$ \\
$\mathrm{Mg \#}$ & $0.904 \pm 0.003$ & $0.906 \pm 0.002$ & $0.907 \pm 0.003$ \\
$\mathrm{Z}_{410}$ & $424 \pm 7 \mathrm{~km}$ & $417 \pm 6 \mathrm{~km}$ & $416 \pm 6 \mathrm{~km}$ \\
$\mathrm{Z}_{660}$ & $660 \pm 2 \mathrm{~km}$ & $659 \pm 2 \mathrm{~km}$ & $658 \pm 2 \mathrm{~km}$ \\
\hline
\end{tabular}

Appalachian mountains, i.e., parts of provinces P6-P9 and T2-T8. The third cluster (green dots) represents an intermediate group of profiles distributed over the central and eastern parts that are sandwiched between red and blue regions. While these features suggest that tectonic regions are mainly controlled by the thermal structure of the continental lithosphere, a compositional signal is also present (section 6.6). For the remainder of the discussion, we will refer to the tectonic regions identified in Figure 8A as the tectonically active West (TAW; red), the central transition regions (CTR; green), and the cratonic-orogenic East (COE; blue). Smoothed outlines of these regions are indicated in the maps and an overview of the values observed for the thermo-chemical parameters is given in Table 3 .

\subsection{Mantle temperature}

For ease of comparison with literature estimates, we rely on the concept of potential temperature, $\mathrm{T}_{\text {pot }}$, which is the temperature of the adiabatic mantle when extended to the Earth's surface (McKenzie \& Bickle, 1988). We compute $\mathrm{T}_{\text {pot }}$ by linear extrapolation of the adiabatic mantle geotherm: $T_{\text {pot }}=T_{\text {lit }}-\nabla \mathrm{T} \cdot \mathrm{Z}_{\mathrm{lit}}$, where we have employed an adiabatic gradient $\nabla \mathrm{T}=\left(\mathrm{T}_{410}-\mathrm{T}_{\text {lit }}\right) /\left(\mathrm{Z}_{410}-\mathrm{Z}_{\text {lit }}\right)$ with $\mathrm{T}_{410}$ and $\mathrm{Z}_{410}$ representing temperature at and depth of the 410 , respectively. Uncertainties on $\mathrm{T}_{\text {pot }}$ average $35{ }^{\circ} \mathrm{C}$ and $43{ }^{\circ} \mathrm{C}$ for Ps and Sp RFs, respectively (Figure $6 \mathrm{C}-\mathrm{D}$ ). Figure $9 \mathrm{~A}$ displays the interpolated values of the mean value of $\mathrm{T}_{\text {pot }}$. As in Figure 8A, we observe a clear east-west trend from low to high potential temperatures, reaching values of 1430$1520{ }^{\circ} \mathrm{C}$ in region TAW, $1360-1470{ }^{\circ} \mathrm{C}$ in CTR, and $1350-1450{ }^{\circ} \mathrm{C}$ in $\mathrm{COE}$, respectively. We find large positive thermal anomalies underneath the Cascade Range (P1), the Basin and Range province (P3), and Yellowstone Hotspot. The same general east-west pattern was also observed in the thermal anomaly maps obtained by Khan et al. (2011) from inversion of surface wave phase velocities, although of lower resolution, by Maguire et al. (2018) from stacking of Ps RFs, and S. M. Hansen et al. (2015) from analysis of surface wave tomographic models. We should note that thermal anomalies constrained by $\mathrm{Sp}$ RFs could be biased by the basalt-rich nature of the inverted compositions (see Figure $6 \mathrm{H}$ ). 
We estimate that in these regions "normal" basalt fractions would cool the mantle locally by up to $\sim 30-50{ }^{\circ} \mathrm{C}$ (cf. supplementary Figure S.16).

\subsection{Lithospheric thickness and structure}

A map of the thickness of the thermal lithosphere is shown in Figure 9B. We emphasize that lithospheric thickness refers to the depth (defined by $\mathrm{Z}_{\mathrm{lit}}$ ) at which the conductive geotherm intercepts the mantle adiabat. There is no apparent discontinuity associated herewith and hence no converted phase; yet, the long-period part of the Sp RFs (cf. supplementary Figure S.15) is affected. Note that uncertainties on thermal lithospheric thickness are generally much smaller for Sp $(17 \mathrm{~km})$ than for Ps RFs $(32 \mathrm{~km})$ (Figure 6EF). This arises because lithospheric Sp RFs are not obscured by crustal reverberations, as is the case for Ps RFs. Consequently, Ps RFs only provide indirect insight into lithospheric structure via the sensitivity of the P410s and P660s to mantle temperature, which is controlled by both $\mathrm{Z}_{\text {lit }}$ and $\mathrm{T}_{\text {lit }}$. However, as S-to-p measurements are sparse, we include the results from Ps RFs for interpolating $\mathrm{Z}_{\mathrm{lit}}$.

The thinnest lithosphere $(79-141 \mathrm{~km})$ is found in region TAW, as also observed in previous studies that considered Ps and/or Sp RFs (e.g., Li et al., 2007; Abt et al., 2010; Lekić et al., 2011; Levander \& Miller, 2012; Hopper et al., 2014; S. M. Hansen et al., 2015). The exact shape of the thin-lithosphere branches that extend across the Rocky Mountains (P5) towards the Central plains (P6) are only constrained by few data points and hence are not interpreted further here. Region CTR shows an intermediate range in lithospheric thickness of $85-187 \mathrm{~km}$ and coincides mostly with the western Great plains (P6), the New Madrid Seismic Zone (e.g., Zhang et al., 2009; C. Chen et al., 2014), and the mid-continental rift system (e.g., Stein et al., 2015). Finally, region COE is, as expected on account of its cratonic and orogenic nature, composed of relatively thick lithosphere $(125-247 \mathrm{~km})$. This negative correlation between potential temperature and lithospheric thickness observed in the maps is clearly visible in Figure 9C and is further illustrated in the tomographic cross sections shown in Figure 11, where lateral variations in thickness go hand-in-hand with variations in S-wave anomalies (see section 6.7) such that thick lithosphere is predominant in "cold" regions, whereas thin lithosphere is found in "hotter" regions.

We should note that some Sp RFs (e.g., 17-JCT, 32-SUSD, and 39-COWI) show complexities in the lithospheric part that are difficult to fit, which could potentially lead to a bias in thermal thickness estimates. These complexities have been attributed to midlithospheric discontinuities (MLDs) that were observed in Sp RFs from North America (e.g., Abt et al., 2010; Miller \& Eaton, 2010; H. Yuan \& Romanovicz, 2010; Lekić \& Fischer, 2014; Kind et al., 2015; Calò et al., 2016) and elsewhere (e.g., Heit et al., 2007; Savage \& Silver, 2008; L. Chen, 2009; Ford et al., 2010; Wölbern et al., 2012; Sodoudi et al., 2013). Processes capable of creating MLDs have been discussed extensively by Selway et al. (2015). In a recent study, Kind et al. (2020) has pointed out that MLDs could result from the use of "inexact" filtering and deconvolution. Instead Kind et al. (2020) directly summed waveforms to obtain RF stacks as a result of which MLDs, for example, were less apparent and point to the importance of careful data processing. While unobjectionable, this is of less importance in this study, inasmuch as the problems that beset imaging and interpretation are avoided in an inversion, where the same processing steps are applied to synthetic and observed data.

\subsection{Mantle composition}

Mantle composition (basalt fraction) primarily affects the sharpness of the 410 and 660 seismic discontinuities through its influence on RF amplitudes rather than the timing of converted waves (see supplementary Figure S.15). This is opposite to the effect of temperature, which primarily affects the depth of the 410 and 660 and, through that, travel time of the converted phases. This separation of sensitivity allows us to decou- 
ple the parameters. Basalt fractions estimated from Ps RFs vary on average from 0 to $25 \%$, i.e., within the Harzburgite to Pyrolite range with uncertainties around 5\% (cf. Figure 6G). In comparison, Sp RF-estimated basalt fractions show larger uncertainties (9.5\%; cf. Figure $6 \mathrm{H})$ and appear to cluster toward the upper end of the prior $(f=50 \%)$, in disagreement with the Ps RF-derived results and other studies (e.g., Khan et al., 2011; Maguire et al., 2018). The inferred basalt-enrichment is likely related to the reduced sensitivity of the S410p to composition, because of the generally small amplitudes of S410p relative to P410s. However, as noted earlier, this only has a small effect on thermal estimates due to the first-order decoupling of temperature and composition. Consequently, we exclude Sp RF-derived information from the compositional map (Figure 9D).

For present purposes, we express composition by means of the $\mathrm{Mg} \#$, which is computed as $\mathrm{Mg} /(\mathrm{Mg}+\mathrm{Fe})$ (molar) (cf. Table 1), where high/low $\mathrm{Mg} \#$ is indicative of depleted/fertile mantle, i.e., low/high basalt fraction, respectively. While most of the mantle across the continent appears to be made up of relatively depleted compositions (Figure 9D), region TAW is found to be slightly more fertile $(f=13 \pm 4.5 \%, \mathrm{Mg} \# \sim 0.90)$ in comparison to regions CTR and COE (COE: $f=10 \pm 3.6 \%, \mathrm{Mg} \# \sim 0.91$ ), similar to the results of Khan et al. (2011). Local enrichment of basalt underneath the continent could correspond to traces of active (Cascadia) and ancient subduction zones (Farallon). The location of these anomalies are in agreement with the results by Maguire et al. (2018).

\subsection{Shear-wave velocity structure}

In the following, we focus on models of isotropic elastic S-wave velocity. Figure 10 shows S-wave velocity images of the upper mantle and MTZ. For comparison, analogous plots for two tomographic models, US-SL-2014 (Schmandt \& Lin, 2014) and SL2013NA (Schaeffer \& Lebedev, 2014), are shown in the supplementary material (Figures S.22S.25). To illustrate lateral variations in structure further, we also present cross sections (Figure 11) along three east-west and north-south profiles (magenta lines in Figure 2C). From these tomographic images, the following observations can be made:

1) S-wave velocity anomalies in the upper mantle $(100-300 \mathrm{~km})$ closely follow the tectonic regionalization and appear to be dominated by the lithospheric signature in that velocities are high/low in regions with a deep/shallow lithosphere, respectively. These observations are particularly apparent in the east-west trending cross sections, where the lithosphere slowly thickens and S-wave velocities decrease when passing from region TAW to CTR underneath the eastern Rocky Mountains flank (P5 to P6). The large variations in lithosphere thickness $(70-250 \mathrm{~km})$ affect the extent and amplitude of the upper mantle low-velocity zone (Figure 8B), including large lateral velocity variations of $\pm 5.1 \%$ at $100 \mathrm{~km}$ depth. Amplitudes aside, similar observations were made in models SL2013NA and US-SL-2014 (supplementary Figures S.22-S.25) and other regional tomographic models (e.g., Grand \& Helmberger, 1984; van der Lee \& Frederiksen, 2005; Nettles \& Dziewonski, 2008; Bensen et al., 2009; H. Yuan \& Romanovicz, 2010; Khan et al., 2011; H. Yuan et al., 2011, 2014; W. Shen \& Ritzwoller, 2016; Krischer et al., 2018).

2) We are able to image mantle features underneath the western margin of the continent (region TAW), where volcanism, accretion, and extensive tectonics are the likely surface expression of ancient and active subduction (e.g., Sonder \& Jones, 1999; Dickinson, 2004; Humphreys, 2009). We observe localized high-velocity anomalies in the north that move further inland and southward at greater depths (Figure 11B) and probably represent fragmented pieces of the Juan de Fuca, Gorda, and Farallon slabs (e.g., Sigloch, 2011; Portner \& Hayes, 2018). We further see a dominant low-velocity band parallel to the Pacific coast, which, at shallow depths, forms a circular structure around the Colorado plateau (P4) that extends towards Yellowstone. Similar features were identified by Becker (2012) in a comparison of tomographic models of the region (Roth et al., 2008; Burdick et al., 2008, 2010; Obrebski et al., 2010, 2011; Schmandt \& Humphreys, 2010, 2011; James et al., 2011; Sigloch, 2011). However, it has to be pointed out that: 1) res- 
olution of our model is low because of reduced data coverage at shallow depth at the flank of the eastern Rocky Mountains (P5); and 2) high basalt fractions, as inferred from Sp RFs, tend to decrease velocity within the MTZ, which exaggerates low-velocity anomalies in regions where Ps RF data points are limited.

3) Considering the central and eastern part (regions CTR and COE), we find multiple high-velocity anomalies that extend to the MTZ, where a roughly north-south aligned band underneath the Great plains (P6) is the most pronounced feature (see east-west cross section). These anomalies could be interpreted as remnant pieces of the Farallon or Laramide slabs, although differences in shape relative to other studies are apparent (e.g., Sigloch, 2011; Schmandt \& Lin, 2014; Porritt et al., 2014).

4) Toward the bottom of the upper mantle, amplitudes of shear-wave anomalies generally decrease, but again increase significantly at and around $400 \mathrm{~km}$ depth as olivine transforms to wadsleyite. Lateral velocity variations are larger than those above and below the transition and emphasizes the importance of considering phase-induced variations in addition to variations arising purely from volumetric velocity perturbations. Structure in and around the MTZ is complex and shows significant topography, particularly on the 410 (Figure 12A). As shown in Figure 12B, we find that the 410 occurs deeper (409-432 km) in "hot" regions (TAW) than in "colder" parts (404-423 km in CTR; 401$422 \mathrm{~km}$ in COE). To compositionally achieve an equivalent 410-depth variation (>30 km), basalt fraction would have to change by $>50 \%$ (see supplementary Figure S.16), which corresponds to more than the total compositional variation observed across the whole study area (Figure 9D). This suggests that composition is of secondary nature in determining topography on the 410 .

5) In contrast to the large peak-to-peak amplitudes of $>30 \mathrm{~km}$ for the 410 , lateral variations of the 660 are only $\pm 5 \mathrm{~km}$ (Figure 12C) and there appears to be little correlation with temperature (Figures 12D). Instead, the dependence of the 660 on temperature and composition is highly non-linear (Figure S.14) and also affected by the transformation of garnet, whose relative importance increases as temperature and basalt fraction increases (e.g., Weidner \& Wang, 1998; Hirose, 2002; Xu et al., 2008; Khan et al., 2009) (see also supplementary Figures S.3 and S.4 of Munch et al. (2018)). Since the Clapeyron slopes for the transformations of garnet and ringwoodite are opposite in sign (Hirose, 2002; Liu et al., 2018), the garnet phase transition would follow the behaviour of the 410 and move deeper in regions of elevated temperature.

6) As a result, MTZ-thickness (Figure 12E) is largely controlled by the topography on the 410 and is thinner in region TAW $(\sim 220-250 \mathrm{~km})$ than in CTR and COE $(\sim 230-260 \mathrm{~km})$. The 410 beneath the western USA (TAW), where two strong depressions separated by a high-elevation band across northern Nevada (see Figure 11B) are observable, agrees well with other Ps and Sp RF studies of the region (Cao \& Lavender, 2010; Tauzin et al., 2013; Gao \& Liu, 2014) and possibly relates to subduction. In contrast, the 660 and hence MTZ thickness varies more across the aforementioned studies. This first and foremost reflects the use of different imaging methods and different reference models in order to convert receiver functions from time to depth. Furthermore, to the east of the Rocky Mountain front (CTR and COE), our inferred 410 and hence MTZ thickness tends to "normal" values, in overall agreement with the continental-scale MTZ model of Gao and Liu (2014). Further to this, Gao and Liu (2014) found, in agreement with Maguire et al. (2018), the MTZ to be locally thicker underneath the Great Plains (P6), which they attributed to remnants of the Farallon or Laramide slabs. Although less prominent, similar MTZ anomalies are also observed here.

\section{Comparison of seismic and thermobarometric constraints}

Assessment of the chemical and petrological characteristics of erupted lavas can provide complementary information to seismic inversions to understand the thermo-chemical structure of the underlying mantle. In order to facilitate this comparison, we compiled whole rock chemical analyses of $\sim 500$ primitive basaltic rocks from the western USA, 
filtered for basalts with eruption ages younger than $5 \mathrm{Ma}$ and with $\mathrm{MgO}$ contents $\geq 8 \mathrm{wt} \%$ (see section S.7 for details). The composition of each sample was inverted in order to solve for the mean pressure and temperature of melt segregation according to the thermobarometer of Lee et al. (2009) to create an internally-consistent database. The resultant estimates on (minimum) lithosphere thickness and mantle potential temperature for each sample have uncertainties of about $17 \mathrm{~km}$ and $50^{\circ} \mathrm{C}$, respectively. Our results are consistent with those of Plank and Forsyth $(2016)$ to within $\left( \pm 20^{\circ} \mathrm{C}\right)$ and $( \pm 15 \mathrm{~km})$ for overlapping localities.

Comparison between petrological and seismological T-P estimates is subject to caveats associated with i) the differing spatial coverage, and ii) the degree to which phase- and/or compositional changes influence the seismic inversion (section 4.1). To account for the locally-confined spatial sensitivity of thermobarometry relative to seismic wavelengths (cf. section 2.2.3), we masked cells beyond a radius of $1.5^{\circ}$ to a sample location. Lithospheric thickness is more difficult to compare given the reduced data coverage in the westernmost USA and the imposed seismic lower bound of $70 \mathrm{~km}$.

With these considerations in mind, the interpolated results from thermobarometry are shown in Figure 13A-B, while the difference to seismically derived potential temperature estimates are presented in Figure 13C-D. The major magmatic provinces are demarcated on the basis of both seismic and petrological inversions (Figure 9 and 13). Thermally anomalous mantle is observed underneath the Cascade range (northern P1) and the Snake River Plain (eastern P2) towards Yellowstone Hotspot, and particularly under the Basin and Range province (P3) in southern Nevada, extending towards the southeast in the Rio Grande rift. Both methods agree on the relative amplitude of thermal anomalies, but differ in absolute values.

The largest temperature discrepancies, in which seismological estimates are 100$250{ }^{\circ} \mathrm{C}$ higher with respect to thermobarometric inversions (cf. Figure 13C-D), are primarily observed along the Cascade arc parallel to the Pacific coast (P1). The petrologicallyderived potential temperatures, $1300-1350{ }^{\circ} \mathrm{C}$, are in agreement with other thermobarometric estimates (Grove et al., 2002; Leeman et al., 2005), whereas temperatures derived from the seismic model may reflect the cumulative effects of increased $\mathrm{H}_{2} \mathrm{O}, f \mathrm{O}_{2}$, and melt fraction underneath this region, none of which are considered. Influx of water and oxidising melts from the downgoing slab into the mantle wedge are characteristics of subduction zones, with the net effect being that increasing $\mathrm{Fe}^{3+}$ in olivine results in increased dissipation of the shear modulus (Cline II et al., 2018), such that more oxidised/waterrich mantle appears seismically slower (and therefore hotter). Other regions show smaller differences $\left(0-100{ }^{\circ} \mathrm{C}\right.$ ), and pertain to largely anhydrous tholeiitic provinces (Snake River Plain, Southern Nevada, and New Mexico) formed by decompression melting of upwelling asthenosphere (Fitton et al., 1991; Feuerbach et al., 1993; Leeman et al., 2009). This agreement therefore empirically verifies the accuracy of the seismic inversion in quantifying the thermo-chemical characteristics of more typical upper mantle.

The strength of this comparison lies in that surficial expressions of thermal anomalies may be linked to deep mantle structures. It also highlights the sensitivity of seismologicallyderived temperature-depth estimates to the specific petrological characeristics of the mantle, which changes with tectonic setting. Correctly accounting for these variations could help solve ambiguity in the chemical and isotopic signatures of eruptive provinces by imaging the thermal state of the underlying mantle in more detailed seismic and petrological surveys in future.

\section{Summary and conclusions}

In this paper, we proposed a methodology for processing, modeling, and inversion of multi-frequency P-to-s and S-to-p converted body waves (receiver functions) and applied it to data recorded by USArray to perform a tomographic study of crust and mantle beneath the North American continent. 
Careful data selection and processing has been found to be a central step in the construction of Sp receiver functions, since these are typically prone to be noisy and sense distinct mantle regions depending on source-receiver configuration. To properly account for this, we binned data into different back-azimuth bins and considered these separately. To further increase the robustness of our Sp RF stacks, we augmented the latter by combining data from USArray reference and transportable stations. Ultimately, only highquality Ps and Sp receiver functions with clear conversions at the Moho, lithosphere, 410, and 660 were retained for inversion. Finally, to ensure consistency between observed and synthetic RF waveform amplitudes, processing of modeled waveforms mimicked that applied to real data in detail. As part of waveform verification, we also conducted a validation of our approach to computing synthetic waveforms in 1-D models by comparing these to full waveform synthetics computed in a 3 -D velocity model.

Relying on a thermodynamic formulation, the forward model consisted of first computing seismic velocity and density models via Gibbs' free energy-minimization, followed by seismic waveform modeling to construct maps of the crust and thermo-chemical mantle structure underneath the contiguous USA. We were able to identify three major tectonic regions based on similarities in radial temperature and S-wave velocity structure:

1) The tectonically active West (TAW), comprising regions west of the Rocky Mountains, is characterised compositionally as more fertile $(\mathrm{Mg} \# \sim 0.90)$, physically by a thinner lithosphere $(100 \pm 23 \mathrm{~km})$, and thermally by higher mantle potential temperatures $\left(1490 \pm 27^{\circ} \mathrm{C}\right)$. Consequently, shallow upper mantle S-wave velocity is strongly diminished (by up to -5\%), shear-attenuation is increased, and the $410-\mathrm{km}$ seismic discontinuity is shifted to greater depths $(424 \pm 7 \mathrm{~km})$.

2) The cratonic-orogenic East (COE), including most of the continent to the east of the Great Plains, is compositionally more depleted $(\mathrm{Mg} \# \sim 0.91)$ and colder (1413 \pm $\left.27^{\circ} \mathrm{C}\right)$, underlain by an overall thicker lithosphere $(208 \pm 33 \mathrm{~km})$. Accordingly, S-wave velocity is higher (by up to $+5 \%$ ), shear-attenuation is decreased, and the 410 appears at shallower depths $(416 \pm 6 \mathrm{~km})$.

3) The Central transition regions (CTR) represent tectonic regions with intermediate properties in-between those of TAW and COE.

Despite being able to image well-known mantle features such as traces of active and ancient subduction or the Yellowstone plume, we note that resolving the exact shape and extent of such 3-D volumetric features by our method is limited by two factors: 1) we do not solve the inverse problem in a fully 3-D framework, but rather use a 1-D formulation to build a 3-D model a posteriori, and 2) converted waves are not directly sensitive to volumetric velocity changes, but rather to velocity contrasts across discontinuities. Further limitations of our method arise from the use of isentropes in modeling mantle thermal structure, end-member compositional model, and the assumption of an equilibrium assemblage configuration. Further, the absence of thermodynamic data, for now, involving melt-, and water-bearing systems might bias our results in certain regions, such as underneath the Cascades arc, as evidenced in the apparent mismatch with petrological estimates. Yet in spite of these limitations, a fully equilibrated, compositionally uniform, adiabatic, and dry mantle nevertheless provides an excellent fit to the observed seismic data. Our combination of geophysically-derived potential temperature- and lithospheric thickness estimates to those obtained from thermobarometric inversions of volcanic rock chemistry in the western USA show first-order agreement, permitting the assessment of broad-scale mantle melting conditions and their magmatic expression. This integrated approach represents a promising avenue for providing multidimensional insight into crustal tectonic structures and regimes and their link with deep mantle processes.

\section{Acknowledgments}

We thank the editor, M. Bostock for editorial handling, the associate editor V. Lekić, $\mathrm{H}$. Yuan, and an anonymous reviewer for valuable comments that helped improve the quality of the manuscript. This study is supported by a grant from the Swiss Federal 
Institute of Technology (ETH, project number 1-003490-000). B. T. has received funding from the European Union's Horizon 2020 research and innovation program under the Marie Sklodowska-Curie grant agreement No. 793824. P. A. S. acknowledges support from the Swiss National Science Foundation via an Ambizione Fellowship (No. 180025). F. D. M. is supported by the Swiss National Science Foundation (Project No. 159907 and 191892). The facilities of Incorporated Research Institutions for Seismology (IRIS) Data Services, and specifically the IRIS Data Management Center, were used for access to waveforms and related metadata. IRIS Data Services are funded through the Seismological Facilities for the Advancement of Geoscience (SAGE) Award of the National Science Foundation under Cooperative Support Agreement EAR-1851048. Data from the transportable array network were made freely available as part of the EarthScope USArray facility, operated by IRIS and supported by the National Science Foundation, under Cooperative Agreements EAR-1261681. Seismic data were downloaded via ObspyDMT (Hosseini \& Sigloch, 2017) and processed using Obspy (Krischer et al., 2015) and the Python-package "rf" (Eulenfeld, 2020). Perple_X is available on www.perplex.ethz.ch and we use the CMAES-implementation by N. Hansen et al. (2019). Maps were created by means of the Basemap Matplotlib Toolkit (matplotlib.org/basemap/). Tomographic mantle models SL2013NA, US-SL-2014, and GyPSuM were downloaded from IRIS-EMC (ds.iris .edu/ds/products/emc/), while model S362ANI and related codes are available on www .Ideo.columbia.edu/ ekstrom/Projects/3D/BK/models.html. Computations were performed on the clusters Euler (ETH) and Piz Daint (CSCS). Computations on Piz Daint were supported by the Swiss National Supercomputing Centre (CSCS) under Project ID s922. We are grateful to M. Afanasiev, M. van Driel, S. Thrastarsson, L. Krischer, and W. Halter for support in simulating 3-D waveforms using the Salvus software package (www.mondaic. com).

\section{References}

Abt, D. L., Fischer, K. M., French, S. W., Ford, H. A., Yuan, H., \& Romanowicz, B. (2010). North American lithospheric discontinuity structure imaged by Ps and Sp receiver functions. J. Geophys. Res., 115(B09301), 1-24. doi: 10.1029/2009JB006914

Afanasiev, M., Boehm, C., vanDriel, M., Krischer, L., Rietmann, M., May, D. A., ... Fichtner, A. (2019). Modular and flexible spectral-element waveform modelling in two and three dimensions. Geophys. J. Int., 216(3), 1675-1692. doi: $10.1093 /$ gji/ggy469

Afonso, J. C., Rawlinson, N., Yang, Y., Schutt, D. L., Jones, A. G., Fullea, J., \& Griffin, W. L. (2016). 3D multiobservable probabilistic inversion for the compositional and thermal structure of the lithosphere and upper mantle: III. Thermochemical tomography in the WesternCentral U.S. J. Geophys. Res., 121 (B10), 7337-7370. doi: 10.1002/2016JB013049

Alibert, C., Michard, A., \& Albarède, F. (1986). Isotope and trace element geochemistry of Colorado Plateau volcanics. Geochim. Cosmochim. Acta, 50(12), 27352750. doi: 10.1016/0016-7037(86)90223-1

Amante, C., \& Eakins, B. W. (2009). Etopo1 1 arc-minute global relief model: Procedures, data sources and analysis. NOAA Technical Memorandum NESDIS NGDC-24. National Geophysical Data Center, NOAA. doi: $10.7289 / \mathrm{V} 5 \mathrm{C} 8276 \mathrm{M}$

Andrews, J., \& Deuss, A. (2008). Detailed nature of the $660 \mathrm{~km}$ region of the mantle from global receiver function data. J. Geophys. Res., 113(B06304). doi: 10 $.1029 / 2007 J B 005111$

Arculus, R. J., \& Gust, D. A. (1995). Regional Petrology of the San Francisco Volcanic Field, Arizona, USA. J. Petrol., 36 (3), 827-861. doi: 10.1093/petrology/ 36.3.827

Artemieva, I. M., \& Mooney, W. D. (2001). Thermal thickness and evolution of Pre- 
cambrian lithosphere: A global study. J. Geophys. Res., 106(B6), 16387-16414. doi: 10.1029/2000JB900439

Bacon, C. R., Bruggman, P. E., Christiansen, R. L., Clynne, M. A., Donnelly-Nolan, J. M., \& Hildreth, W. (1997). Primitive magmas at five Cascade volcanic fields: melts from hot, heterogeneous sub-arc mantle. Can. Mineral., 35(2), 397-423.

Bagheri, A., Khan, A., Al-Attar, D., Crawford, O., \& Giardini, D. (2019). Tidal response of Mars constrained from laboratory-based viscoelastic dissipation models and geophysical data. J. Geophys. Res.: Planets, 124. doi: 10.1029/2019JE006015

Beard, B. L., \& Glazner, A. F. (1998). Petrogenesis of isotopically unusual Pliocene olivine leucitites from Deep Springs Valley, California. Contrib. Mineral. Petrol., 133, 402-417. doi: 10.1007/s004100050462

Becker, T. W. (2012). On recent seismic tomography for the western United States. Geochem. Geophys. Geosyst., 13(Q01W10). doi: 10.1029/2011GC003977

Bensen, G. D., Ritzwoller, M. H., \& Yang, Y. (2009). A 3-D shear velocity model of the crust and uppermost mantle beneath the United States from ambient seismic noise. Geophys. J. Int., 177, 1177-1196. doi: 10.1111/j.1365-246X.2009.04125.x

Bercovici, D., \& Karato, S.-I. (2003). Whole-mantle convection and the transitionzone water filter. Nature, 425(6953), 39-44.

Bina, C. R., \& Helffrich, G. (1994). Phase transition Clapeyron slopes and transition zone seismic discontinuity topography. J. Geophys. Res., 99 (B8), 15853-15860. doi: $10.1029 / 94 J B 00462$

Bock, G. (1994). Multiples as precursors to S, SKS and ScS. Geophys. J. Int., 119 , 421-427.

Boyce, A., Bastow, I. D., Golos, E. M., Rondenay, S., Burdick, S., \& van der Hilst, R. (2019). Variable modification of continental lithosphere during the Proterozoic Grenville orogeny: Evidence from teleseismic P-wave tomography. Earth Planet. Sci. Lett., 525(115763). doi: 10.1016/j.epsl.2019.115763

Browne, B., Bursik, M., Deming, J., Louros, M., Martos, A., \& Stine, S. $\quad$ (2010). Eruption chronology and petrologic reconstruction of the ca. $8500 \mathrm{yr}$ B.P. eruption of Red Cones, southern Inyo chain, California. GSA Bulletin, 122(9-10), 1401-1422. doi: 10.1130/B30070.1

Buehler, J. S., \& Shearer, P. M. (2017). Uppermost mantle seismic velocity structure beneath USArray. J. Geophys. Res. Solid Earth, 122, 436-448. doi: 10 $.1002 / 2016 J B 013265$

Burdick, S., Li, C., Martynov, V., Cox, T., Eakins, J., Mulder, T., ... van der Hilst, R. D. (2008). Upper Mantle Heterogeneity beneath North America from Travel Time Tomography with Global and USArray Transportable Array Data. Seismol. Res. Lett., 79(3), 384-392. doi: 10.1785/gssrl.79.3.384

Burdick, S., van der Hilst, R. D., Vernon, F. L., Martynov, V., Cox, T., Eakins, J., .. Pavlis, G. L. (2010). Model Update January 2010: Upper Mantle Heterogeneity beneath North America from Traveltime Tomography with Global and USArray Transportable Array Data. Seismol. Res. Lett., 81(5), 689-693. doi: 10.1785/gssrl.81.5.689

Calò, M., Bodin, T., \& Romanowicz, B. (2016). Layered structure in the upper mantle across North America from joint inversion of long and short period seismic data. Earth Planet. Sci. Lett., 449, 164-175. doi: 10.1016/j.epsl.2016.05.054

Cao, A., \& Lavender, A. (2010). High-resolution transition zone structures of the Goreda Slab beneath the western United States: Implication for deepwater subduction. J. Geophys. Res., 115(B07301), 1-13. doi: 10.1029/ 2009JB006876

Chen, C., Zhao, D., \& Wu, S. (2014). Crust and upper mantle structure of the New Madrid Seismic Zone: Insight into intraplate earthquakes. Phys. Earth Planet. 
Inter., 230, 1-14. doi: 10.1016/j.pepi.2014.01.016

Chen, C., Zhao, D., \& Wu, S. (2015). Tomographic imaging of the Cascadia subduction zone: Constraints on the Juan de Fuca slab. Tectonophysics, 648, 7388. doi: $10.1016 /$ j.tecto.2015.02.012

Chen, L. (2009). Lithospheric structure variations between the eastern and central North China Craton from S- and P-receiver function migration. Phys. Earth Planet. Inter., 173, 216-227. doi: 10.1016/j.pepi.2008.11.011

Clark, A. N., \& Lesher, C. E. (2017). Elastic properties of silicate melts: Implications for low velocity zones at the lithosphere-asthenosphere boundary. Sci. Adv., 3(12), 1-5. doi: 10.1126/sciadv.1701312

Cline II, C. J., Faul, U. H., David, E. C., Berry, A. J., \& Jackson, I. (2018). Redoxinfluenced seismic properties of upper-mantle olivine. Nature, 555(7696), 355358. doi: 10.1038/nature25764

Cole, E. D. (1989). Petrogenesis of late Cenozoic alkalic basalt near the eastern boundary of the Basin and Range, upper Grand Wash trough (Unpublished master's thesis). Las Vegas, University of Nevada.

Connolly, J. A. D. (2009). The geodynamic equation of state: What and how. Geochem. Geophys. Geosyst., 10(10), 1-19. doi: 10.1029/2009GC002540

Connolly, J. A. D., \& Khan, A. (2016). Uncertainty of mantle geophysical properties computed from phase equilibrium models. Geophys. Res. Lett., 43, 1-9. doi: 10 .1002/2016GL068239

Cottaar, S., \& Deuss, A. (2016). Large-scale mantle discontinuity topography beneath Europe: Signature of akimotoite in subducting slabs. J. Geophys. Res.: Solid Earth, 121 (1), 279-292. doi: 10.1002/2015JB012452

Crotwell, H. P., Owens, T. J., \& Ritsema, J. (1999). The TauP Toolkit: Flexible seismic travel-time and ray-path utilities. Seismol. Res. Lett., 70, 154-160. doi: 10.1785/gssrl.70.2.154

Dickinson, W. R. (2004). Evolution of the North American Cordillera. Annu. Rev. Earth Planet. Sci., 32, 13-45. doi: 10.1146/annurev.earth.32.101802.120257

Dueker, K. G., \& Sheehan, A. F. (1997). Mantle discontinuity structure from midpoint stacks of converted $\mathrm{P}$ to $\mathrm{S}$ waves across the Yellowstone hotspot track. $J$. Geophys. Res., 102(B4), 8313-8327. doi: 10.1029/96JB03857

Dungan, M. A., Lindstrom, M. M., McMillan, N. J., Moorbath, S., Hoefs, J., \& Haskin, L. A. (1986). Open system magmatic evolution of the Taos Plateau volcanic field, northern New Mexico: 1 . The petrology and geochemistry of the Servilleta Basalt. J. Geophys. Res., 91(B6), 5999-6028. doi: 10.1029/JB091iB06p05999

Dziewonski, A. M., \& Anderson, D. L. (1981). Preliminary reference Earth model. Phys. Earth Planet. Inter., 25, 297-356. doi: 10.1016/0031-9201(81)90046-7

Dziewonski, A. M., Chou, T.-A., \& Woodhouse, J. H. (1981). Determination of earthquake source parameters from waveform data for studies of global and regional seismicity. J. Geophys. Res., 86(B4), 2825-2852. doi: 10.1029/JB086iB04p02825

Earle, P. S., \& Shearer, P. M. (1994). Characterization of Global Seismograms Using an Automatic-Picking Algorithm. Bull. Seismol. Soc. Am., 84(2), 366-376.

Eaton, D. W., Darbyshire, F., Evans, R. L., Grütter, H., Jones, A. G., \& Yuan, X. (2009). The elusive lithosphere-asthenosphere boundary (LAB) beneath cratons. Lithos, 109 (1-2), 1-22. doi: 10.1016/j.lithos.2008.05.009

Efron, B., \& Tibshirani, R. (1991). Statistical data analysis in the computer age. Science, 253(5018), 390-395. doi: 10.1126/science.253.5018.390

Eilon, Z., Fischer, K. M., \& Dalton, C. A. (2018). An adaptive Bayesian inversion for upper-mantle structure using surface waves and scattered body waves. Geophys. J. Int., 214, 232-253. doi: 10.1093/gji/ggy137

Ekström, G., Nettles, M., \& Dziewonski, A. M. (2012). The global CMT project 2004-2010: Centroid-moment tensors for 13,017 earthquakes. Phys. Earth 
Planet. Inter., 200-201, 1-9. doi: 10.1016/j.pepi.2012.04.002

Eulenfeld, T. (2020). rf: Receiver function calculation in seismology. J. Open Source Softw., 5(48), 1808. doi: 10.21105/joss.01808

Farmer, G. L., Glazner, A. F., Wilshire, H. G., Wooden, J. L., Pickthom, W. J., \& Katz, M. (1995). Origin of late Cenozoic basalts at the Cima volcanic field, Mojave Desert, California. J. Geophys. Res., 100(B5), 8399-8415. doi: 10.1029/95JB00070

Farra, V., \& Vinnik, L. (2000). Upper mantle stratification by P and S receiver functions. Geophys. J. Int., 141(3), 699-712. doi: 10.1046/j.1365-246x.2000.00118 . $\mathrm{x}$

Feldstein, S. N., \& Lange, R. A. (1999). Pliocene Potassic Magmas from the Kings River Region, Sierra Nevada, California: Evidence for Melting of a SubductionModified Mantle. J. Petrol., 40(8), 1301-1320. doi: 10.1093/petroj/40.8.1301

Fenneman, N. M. (1928). Physiographic divisions of the United States. Ann. Assoc. Am. Geogr., 18(4), 261-353.

Férot, A., \& Bolfan-Casanova, N. (2012). Water storage capacity in olivine and pyroxene to $14 \mathrm{GPa}$ : Implications for the water content of the Earth's upper mantle and nature of seismic discontinuities. Earth Planet. Sci. Lett., 349-350, 218-230. doi: 10.1016/j.epsl.2012.06.022

Feuerbach, D. L., Smith, E., Walker, J. D., \& Tangeman, J. A. (1993). The role of the mantle during crustal extension: Constraints from geochemistry of volcanic rocks in the Lake Mead area, Nevada and Arizona. Geol. Soc. Am. Bull., 105(12), 1561-1575. doi: 10.1130/0016-7606(1993)105〈1561: TROTMD $>2.3 . \mathrm{CO} ; 2$

Fitton, J. G., James, D., \& Leeman, W. P. (1991). Basic Magmatism Associated With Late Cenozoic Extension in the Compositional Variations in Space and Time. J. Geophys. Res., 96(B8), 13693-13711. doi: 10.1029/91JB00372

Flanagan, M. P., \& Shearer, P. M. (1998). Global mapping of topography on transition zone velocity discontinuities by stacking SS precursors. J. Geophys. Res., 103(B2), 2673-2692. doi: 10.1029/97JB03212

Ford, H. A., Fischer, K. M., Abt, D. L., Rychert, C. A., \& Elkins-Tanton, L. T. (2010). The lithosphereasthenosphere boundary and cratonic lithospheric layering beneath Australia from Sp wave imaging. Earth Planet. Sci. Lett., 300 (3), 299-310. doi: 10.1016/j.epsl.2010.10.007

Freitas, D., Mathilake, G., Schiavi, F., Chantel, J., Bolfan-Casanova, N., Bouhifd, M. A., \& Andrault, D. (2017). Experimental evidence supporting a global melt layer at the base of the Earth's upper mantle. Nat. Commun., 8(2186). doi: $10.1038 / \mathrm{s} 41467-017-02275-9$

Fuchs, K., \& Müller, G. (1971). Computation of synthetic seismograms with the reflectivity method and comparison with observations. Geophys. J. Int., 23(4), 417-433. doi: 10.1111/j.1365-246X.1971.tb01834.x

Gao, S. S., \& Liu, K. H. (2014). Mantle transition zone discontinuities beneath the contiguous United States. J. Geophys. Res.: Solid Earth, 119, 6452-6468. doi: 10.1002/2014JB011253

Geissler, W. H., Sodoudi, F., \& Kind, R. (2010). Thickness of the central and eastern European lithosphere as seen by S receiver functions. Geophys. J. Int., 181(2), 604-634. doi: 10.1111/j.1365-246X.2010.04548.x

Glazner, A. F., Lang Farmer, G., Hughes, W. T., Wooden, J. L., \& Pickthorn, W. (1991). Contamination of basaltic magma by mafic crust at Amboy and Pisgah Craters, Mojave Desert, California. J. Geophys. Res., 96(B8), 13673-13691. doi: 10.1029/91JB00175

Grand, S. P., \& Helmberger, D. V. (1984). Upper mantle shear structure of North America. Geophys. J. Int., 76(2), 399-438. doi: 10.1111/j.1365-246X.1984 .tb05053.x

Green, D. H., Hibberson, W. O., Kovács, I., \& Rosenthal, A. (2010). Water and its 
influence on the lithosphereasthenosphere boundary. Nature, 467, 448-451. doi: 10.1038/nature09369

Green, N. L., \& Sinha, A. K. (2005). Consequences of varied slab age and thermal structure on enrichment processes in the sub-arc mantle of the northern Cascadia subduction system. J. Volcanol. Geotherm. Res., 140(1-3), 107-132. doi: 10.1016/j.jvolgeores.2004.07.017

Grove, T. L., Parman, S. W., Bowring, S. A., Price, R. C., \& Baker, M. B. $\quad$ (2002). The role of an $\mathrm{H}_{2} \mathrm{O}$-rich fluid component in the generation of primitive basaltic andesites and andesites from the Mt. Shasta region, N California. Contrib. Mineral. Petrol., 142, 375-396. doi: 10.1007/s004100100299

Hammersley, L., \& De Paolo, D. J. (2006). Isotopic and geophysical constraints on the structure and evolution of the Clear Lake volcanic system. J. Volcanol. Geotherm. Res., 153, 331-356. doi: 10.1016/j.jvolgeores.2005.12.003

Hansen, N., Akimoto, Y., \& Baudis, P. (2019). CMA-ES/pycma on Github. Zenodo, DOI:10.5281/zenodo.2559634. doi: 10.5281/zenodo.2559634

Hansen, N., \& Ostermeier, A. (2001). Completely derandomized self-adaptation in evolution strategies. Evol. Comput., 9(2), 159-195. doi: 10.1162/ 106365601750190398

Hansen, S. M., Dueker, K., \& Schmandt, B. (2015). Thermal classification of lithospheric discontinuities beneath USArray. Earth Planet. Sci. Lett., 431, 36-47. doi: 10.1016/j.epsl.2015.09.009

Hastings, W. K. (1970). Monte Carlo sampling methods using Markov chains and their applications. Biometrika, 57(1), 97-109. doi: 10.2307/2334940

Heit, B., Sodoudi, F., Yuan, X., Bianchi, M., \& Kind, R. (2007). $\quad$ An S receiver function analysis of the lithospheric structure in South America. Geophys. Res. Lett., 34(L14307). doi: 10.1029/2007GL030317

Helffrich, G. (2000). Topography of the Transition Zone Discontinuities. Rev. Geophys., 38(1), 141-158. doi: 10.1029/1999RG000060

Helffrich, G. R., \& Wood, B. J. (2001). The Earth's mantle. Nature, 412(6613), 219229. doi: $10.1038 / 35087500$

Hill, R. (1952). The elastic behaviour of a crystalline aggregate. Proc. Phys. Soc. A, 65, 349-354. doi: 10.1088/03701298/65/5/307

Hirose, K. (2002). Phase transitions in pyrolitic mantle around 670-km depth: implications for upwelling of plumes from the lower mantle. J. Geophys. Res., 107(B4). doi: 10.1029/2001JB000597

Hirschmann, M. M. (2006). Water, Melting, and the Deep Earth $\mathrm{H}_{2} \mathrm{O}$ Cycle. Annu. Rev. Earth Planet. Sci., 34, 629-653. doi: 10.1146/annurev.earth.34.031405 .125211

Hoffer, J. M. (1988). Late Cenozoic basalts of southwestern New Mexico. In G. H. Mack, T. F. Lawton, \& S. G. Lucas (Eds.), Cretaceous and Laramide Tectonic Evolution of Southwestern New Mexico (p. 119-122). $\quad$ New Mexico Geological Society 39th Annual Fall Field Conference Guidebook.

Hoffman, P. F. (1988). United plates of America, the birth of a craton: Early Proterozoic assembly and growth of Laurentia. Annu. Rev. Earth Planet. Sci., 16, 543-603. doi: 10.1146/annurev.ea.16.050188.002551

Hoffman, P. F. (1989). Precambrian geology and tectonic history of North America. In A. W. Bally \& A. R. Palmer (Eds.), The Geology of North America An Overview, vol. A. Boulder, CO: The Geological Society of America.

Hopper, E., Ford, H. A., Fischer, K. M., Lekić, V., \& Fouch, M. J. (2014). The lithosphereasthenosphere boundary and the tectonic and magmatic history of the northwestern United States. Earth Planet. Sci. Lett., 402, 69-81. doi: 10.1016/j.epsl.2013.12.016

Hosseini, K., \& Sigloch, K. (2017). ObspyDMT: a Python toolbox for retrieving and processing large seismological data sets. Solid Earth, 8, 1047-1070. doi: 10 $.5194 / \mathrm{se}-8-1047-2017$ 
Houser, C., Masters, G., Shearer, P., \& Laske, G. (2008). Shear and compressional velocity models of the mantle from cluster analysis of long-period waveforms. Geophys. J. Int., 174, 195-212. doi: 10.1111/j.1365-246X.2008.03763.x

Humphreys, E. (2009). Relation of flat subduction to magmatism and deformation in the western United States. In Backbone of the Americas: Shallow Subduction, Plateau Uplift, and Ridge and Terrane Collision. Geological Society of America. doi: 10.1130/2009.1204(04)

Jackson, I., \& Faul, U. H. (2010). Grainsize-sensitive viscoelastic relaxation in olivine: towards a robust laboratory-based model for seismological application. Phys. Earth Planet. Inter., 183(1-2), 151-163. doi: 10.1016/j.pepi.2010.09.005

James, D. E., Fouch, M. J., Carlson, R. W., \& Roth, J. B. (2011). Slab fragmentation, edge flow and the origin of the Yellowstone hotspot track. Earth Planet. Sci. Lett., 311(1-2), 124-135. doi: 10.1016/j.epsl.2011.09.007

Jaupart, C., \& Mareschal, J.-C. (1999). Thermal structure and thickness of continental roots. Lithos, 48, 93-114. doi: 10.1016/S0419-0254(99)80007-X

Karato, S., Olugboji, T., \& Park, J. (2015). Mechanisms and geologic significance of the mid-lithosphere discontinuity in the continents. Nat. Geosci., 8, 509-514. doi: 10.1038/NGEO2462

Karato, S., \& Park, J. (2019). On the Origin of the Upper Mantle Seismic Discontinuities. In H. Yuan \& B. Romanowicz (Eds.), Lithospheric Discontinuities. Washington, DC: American Geophysical Union. doi: 10.1002/9781119249740 .ch1

Kawakatsu, H., Kumar, P., Takei, Y., Shinohara, M., Kanazawa, T., Araki, E., \& Suyehiro, K. (2009). Seismic Evidence for Sharp LithosphereAsthenosphere Boundaries of Oceanic Plates. Science, 324(5926), 499-502. doi: 10.1126/science.1169499

Kempton, P. D., Dungan, M. A., \& Blanchard, D. P. (1987). Petrology and geochemistry of xenolith-bearing alkalic basalts from the Geronimo Volcanic Field, southeast Arizona; Evidence for polybaric fractionation and implications for mantle heterogeneity. In Mantle Metasomatism and Alkaline Magmatism. Geological Society of America. doi: 10.1130/SPE215-p347

Kennett, B. L. N., \& Engdahl, E. R. (1991). Traveltimes for global earthquake location and phase identification. Geophys. J. Int., 105, 429-465. doi: 10.1111/ j.1365-246X.1991.tb06724.x

Khan, A., Boschi, L., \& Connolly, J. A. D. (2009). On mantle chemical and thermal heterogeneities and anisotropy as mapped by inversion of global surface wave data. J. Geophys. Res., 114(B09305), 1-21. doi: 10.1029/2009JB006399

Khan, A., \& Shankland, T. J. (2012). A geophysical perspective on mantle water content and melting: Inverting electromagnetic sounding data using laboratory-based electrical conductivity profiles. $\quad$ Earth Planet. Sci. Lett., 317-318, 27-43. doi: 10.1016/j.epsl.2011.11.031

Khan, A., Zunino, A., \& Deschamps, F. (2011). The thermochemical and physical structure beneath the North American continent from Bayesian inversion of surfacewave phase velocities. J. Geophys. Res., 116(B09304), 1-23. doi: 10.1029/2011JB008380

Kind, R., Mooney, W. D., \& Yuan, X. (2020). New insights into the structural elements of the upper mantle beneath the contiguous United States from S-to-P converted seismic waves. Geophys. J. Int., 222, 646-659. doi: $10.1093 /$ gji/ggaa203

Kind, R., Yuan, X., \& Kumar, P. (2012). Seismic receiver functions and the lithosphereasthenosphere boundary. Tectonophysics, 536-537, 25-43. doi: 10.1016/ j.tecto.2012.03.005

Kind, R., Yuan, X., Mechie, J., \& Sodoudi, F. (2015). Structure of the upper mantle in the north-western and central United States from USArray S-receiver functions. Solid Earth, 6, 957970. doi: 10.5194/se-6-957-2015 
Knapmeyer-Endrun, B., Krüger, F., Geissler, W. H., \& PASSEQ Working Group. (2017). Upper mantle structure across the Trans-European Suture Zone imaged by S-receiver functions. $\quad$ Earth Planet. Sci. Lett., 458, 429-441. doi: 10.1016/j.epsl.2016.11.011

Kohlstedt, D., Keppler, H., \& Rubie, D. (1996). Solubility of water in the $\alpha, \beta$ and $\gamma$ phases of $(\mathrm{Mg}, \mathrm{Fe})_{2} \mathrm{SiO}_{4} . \quad$ Contrib. Mineral. Petrol., 123(345357). $\quad$ doi: 10 $.1007 / \mathrm{s} 004100050161$

Kosarev, G., Kind, R., Sobolev, S. V., Yuan, X., Hanka, W., \& Oreshin, S. (1999). Seismic Evidence for a Detached Indian Lithospheric Mantle Beneath Tibet. Science, 283(5406), 1306-1309. doi: 10.1126/science.283.5406.1306

Krischer, L., Fichtner, A., Boehm, C., \& Igel, H. (2018). Automated Large-Scale Full Seismic Waveform Inversion for North America and the North Atlantic. J. Geophys. Res.: Solid Earth, 123, 5902-5928. doi: 10.1029/2017JB015289

Krischer, L., Megies, T., Barsch, R., Beyreuther, M., Lecocq, T., Caudron, C., \& Wassermann, J. (2015). ObsPy: a bridge for seismology into the scientific Python ecosystem. Comput. Sci. Discov., 8(1). doi: 10.1088/1749-4699/8/1/ 014003

Kumar, P., Yuan, X., Kind, R., \& Kosarev, G. (2005). The lithosphereasthenosphere boundary in the Tien Shan-Karakoram region from S receiver functions: Evidence for continental subduction. Geophys. Res. Lett., 32(L07305), 1-4. doi: 10.1029/2004GL022291

Kustowski, B., Ekström, G., \& Dziewonski, A. M. (2008). Anisotropic shear-wave velocity structure of the Earth's mantle: A global model. J. Geophys. Res., 113(B06306). doi: 10.1029/2007JB005169

Langmuir, C. H., Klein, E. M., \& Plank, T. (1992). Petrological Systematics of MidOcean Ridge Basalts: Constraints on Melt Generation Beneath Ocean Ridges. In Mantle Flow and Melt Generation at MidOcean Ridges (p. 183-280). American Geophysical Union (AGU). doi: 10.1029/GM071p0183

Langston, C. A. (1979). Structure Under Mount Rainier, Washington, Inferred From Teleseismic Body Waves. J. Geophys. Res., 84(B9), 4749-4762. doi: 10.1029/ JB084iB09p04749

Laske, G., Masters, G., Ma, Z., \& Pasyanos, M. (2013). Update on CRUST1.0 - A 1degree Global Model of Earth's Crust. In Geophys. Res. Abstracts, 15, Abstract EGU2013-2658.

Lau, H., \& Faul, U. (2019). Anelasticity from seismic to tidal timescales: Theory and observations. Earth Planet. Sci. Lett., 508, 18-29. doi: 10.1016/j.epsl.2018 .12 .009

Lawrence, J. F., \& Shearer, P. M. (2006). A global study of transition zone thickness using receiver functions. J. Geophys. Res., 111(B06307), 1-10. doi: 10 $.1029 / 2005 J B 003973$

Lee, C.-T. A., Luffi, P., Plank, T., Dalton, H., \& Leeman, W. P. (2009). Constraints on the depths and temperatures of basaltic magma generation on Earth and other terrestrial planets using new thermobarometers for mafic magmas. Earth Planet. Sci. Lett., 279(1-2), 20-33. doi: 10.1016/j.epsl.2008.12.020

Leeman, W. P., Lewis, J. F., Evarts, R. C., Conrey, R. M., \& Streck, M. J. (2005). Petrologic constraints on the thermal structure of the Cascades arc. J. Volcanol. Geotherm. Res., 140(1-3), 67-105. doi: 10.1016/j.jvolgeores.2004.07.016

Leeman, W. P., Schutt, D. L., \& Hughes, S. S. (2009). Thermal structure beneath the Snake River Plain: Implications for the Yellowstone hotspot. J. Volcanol. Geotherm. Res., 188(1-3), 5767. doi: 10.1016/j.jvolgeores.2009.01.034

Lekić, V., Cottaar, S., Dziewonski, A., \& Romanowicz, B. (2012). Cluster analysis of global lower mantle tomography: A new class of structure and implications for chemical heterogeneity. Earth Planet. Sci. Lett., 357-358, 68-77. doi: 10.1016/j.epsl.2012.09.014

Lekić, V., \& Fischer, K. M. (2014). Contrasting lithospheric signatures across the 
western United States revealed by Sp receiver functions.

Earth Planet. Sci. Lett., 402, 90-98. doi: 10.1016/j.epsl.2013.11.026

Lekić, V., \& Fischer, K. M. (2017). Interpreting spatially stacked Sp receiver functions. Geophys. J. Int., 210(2), 874-886. doi: 10.1093/gji/ggx206

Lekić, V., French, S. W., \& Fischer, K. M. (2011). Lithospheric Thinning Beneath Rifted Regions of Southern California. Science, 334, 783-787. doi: 10.1126/ science. 1208898

Lekić, V., \& Romanowicz, B. (2011). Tectonic regionalization without a priori information: A cluster analysis of upper mantle tomography. Earth Planet. Sci. Lett., 308, 151-160. doi: 10.1016/j.epsl.2011.05.050

Levander, A., \& Miller, M. S. (2012). Evolutionary aspects of lithosphere discontinuity structure in the western U.S. Geochem. Geophys. Geosyst., 13(7), 1-22. doi: 10.1029/2012GC004056

Li, X., Yuan, X., \& Kind, R. (2007). The lithosphereasthenosphere boundary beneath the western United States. Geophys. J. Int., 170, 700-710. doi: 10.1111/ j.1365-246X.2007.03428.x

Ligorría, J. P., \& Ammon, C. J. (1999). Iterative Deconvolution and ReceiverFunction Estimation. Bull. Seismol. Soc. Am., 89(5), 1395-1400.

Liu, H., Wang, W., Jia, X., Leng, W., Zhongqing, W., \& Sun, D. (2018). The combined effects of post-spinel and post-garnet phase transitions on mantle plume dynamics. $\quad$ Earth Planet. Sci. Lett., 496, 80-88. doi: 10.1016/ j.epsl.2018.05.031

Liu, K. H. (2003). Effects of inelasticity on the apparent depth and detectability of seismic discontinuities in the mantle. Geophys. Res. Lett., 30(9), 1455. doi: 10 $.1029 / 2002 \mathrm{GL} 015264$

Lowry, A. R., \& Peréz-Gussinyé, M. (2011). The role of crustal quartz in controlling Cordilleran deformation. Nature, 471, 353-357. doi: 10.1038/nature09912

Ma, X., \& Lowry, A. R. (2017). USArray Imaging of Continental Crust in the Conterminous United States. Tectonics, 36, 2882-2902. doi: 10.1002/ 2017TC004540

MacQueen, J. B. (1967). Some Methods for classification and Analysis of Multivariate Observations. In Proceedings of 5th Berkeley Symposium on Mathematical Statistics and Probability. Band 1 (p. 281-297). University of California Press.

Maguire, R., Ritsema, J., \& Goes, S. (2018). Evidence of Subduction-Related Thermal and Compositional Heterogeneity Below the United States From Transition Zone Receiver Functions. Geophys. Res. Lett., 45, 8913-8922. doi: 10.1029/2018GL078378

Makushkina, A., Tauzin, B., Tkalčić, H., \& Thybo, H. (2019). The Mantle Transition Zone in Fennoscandia: Enigmatic High Topography Without Deep Mantle Thermal Anomaly. Geophys. Res. Lett., 46, 1-11. doi: 10.1029/2018GL081742

McKenzie, D., \& Bickle, M. (1988). The volume and composition of melt generated by extension of the lithosphere. J. Petrol., 29(3), 625-679. doi: 10.1093/ petrology/29.3.625

Metropolis, N., Rosenbluth, A. W., Rosenbluth, M. N., Teller, A. H., \& Teller, E. (1953). Equation of state calculations by fast computing machines. J. Chem. Phys., 21 (6), 1087-1092. doi: 10.1063/1.1699114

Miller, M. S., \& Eaton, D. W. (2010). Formation of cratonic mantle keels by arc accretion: Evidence from S receiver functions. Geophys. Res. Lett., 37(L18305), 1-5. doi: 10.1029/2010GL044366

Monna, S., Montuori, C., Piromallo, C., \& Vinnik, L. (2019). Mantle Structure in the Central Mediterranean Region From P and S Receiver Functions. Geochem. Geophys. Geosyst., 20. doi: 10.1029/2019GC008496

Mooney, W. D., \& Kaban, M. K. (2010). The North American upper mantle: Density, composition, and evolution. J. Geophys. Res., 115(B12424), 1-24. doi: 10 

.1029/2010JB000866

Mordick, B. E., \& Glazner, A. (2006). Clinopyroxene thermobarometry of basalts from the Coso and Big Pine volcanic fields, California. Contrib. Mineral. Petrol., 152(1), 111-124. doi: 10.1007/s00410-006-0097-0

Mosegaard, K., \& Tarantola, A. (1995). Monte Carlo sampling of solutions to inverse problems. J. Geophys. Res., 100(B7), 12431-12447. doi: 10.1029/94JB03097

Mosegaard, K., \& Tarantola, A. (2002). Probabilistic Approach to Inverse Problems. In International handbook of earthquake and engineering seismology (p. 237-265). Academic Press.

Müller, G. (1985). The reflectivity method: a tutorial. J. Geophys., 58, 153-174.

Munch, F. D., Khan, A., Tauzin, B., van Driel, M., \& Giardini, D. (2020). Seismological evidence for thermo-chemical heterogeneity in Earth's continental mantle. Earth Planet. Sci. Lett., 539, 1-9. doi: 10.1016/j.epsl.2020.116240

Munch, F. D., Khan, A., Tauzin, B., Zunino, A., \& Giardini, D. (2018). Stochastic inversion of PtoS converted waves for mantle thermal and compositional structure: methodology and application. J. Geophys. Res.: Solid Earth, 123, 10706-10726. doi: 10.1029/2018JB016032

Nakata, J. K. (1980). Distribution and petrology of the Anderson-Coyote Reservoir volcanic rocks, California. U.S. Geological Survey Open-File Report, 80-1256.

Nelson, P. L., \& Grand, S. P. (2018). Lower-mantle plume beneath the Yellowstone hotspot revealed by core waves. Nat. Geosci., 11, 280-284. doi: 10.1038/s41561 $-018-0075-\mathrm{y}$

Nettles, M., \& Dziewonski, A. (2008). Radially anisotropic shear velocity structure of the upper mantle globally and beneath North America. J. Geophys. Res., 113(B02303). doi: 10.1029/2006JB004819

Obrebski, M., Allen, R. M., Pollitz, F., \& Hung, S.-H. ～(2011). Lithosphereasthenosphere interaction beneath the western United States from the joint inversion of body-wave travel- times and surface-wave phase velocities. Geophys. J. Int., 185(2), 1003-1021. doi: 10.1111/j.1365-246X.2011.04990.x

Obrebski, M., Allen, R. M., Xue, M., \& Hung, S.-H. (2010). Slab-plume interaction beneath the Pacific Northwest. Geophys. Res. Lett., 37(L14305). doi: 10.1029/ 2010GL043489

Peters, T. J., Menzies, M., Thirlwall, M., \& Kyle, P. R. (2008). ZuniBandera volcanism, Rio Grande, USA - Melt formation in garnet- and spinel-facies mantle straddling the asthenosphere-lithosphere boundary. Lithos, 102(1-2), 295-315. doi: $10.1016 /$ j.lithos.2007.08.006

Plank, T., \& Forsyth, D. W. (2016). Thermal structure and melting conditions in the mantle beneath the Basin and Range province from seismology and petrology. Geochem. Geophys. Geosyst., 17, 1312-1338. doi: 10.1002/2015GC006205

Porritt, R. W., Allen, R. M., \& Pollitz, F. F. (2014). Seismic imaging east of the Rocky Mountains with USArray. Earth Planet. Sci. Lett., 402, 16-25. doi: 10 $.1016 /$ j.epsl.2013.10.034

Portner, D. E., \& Hayes, G. P. (2018). Incorporating teleseismic tomography data into models of upper mantle slab geometry. Geophys. J. Int., 215(1), 325-332. doi: $10.1093 /$ gji/ggy279

Rader, E., Emry, E., Schmerr, N., Frost, D., Cheng, C., Menard, J., ... Geist, D. (2015). Characterization and Petrological Constraints of the Midlithospheric Discontinuity. ，Geochem. Geophys. Geosyst., 16, 3484-3504. doi: 10.1002/2015GC005943

Ringwood, A. (1975). Composition and Petrology of the Earth's Mantle. New York: McGraw-Hill.

Rogers, N. W., Hawkesworth, C. J., \& Ormerod, D. S. (1995). Late Cenozoic basaltic magmatism in the Western Great Basin, California and Nevada. $J$. Geophys. Res., 100(B6), 10287-10301. doi: 10.1029/94JB02738 
Romanowicz, B. A., \& Mitchell, B. J. (2015). Deep Earth Structure: Q of the Earth from Crust to Core. In G. Schubert (Ed.), Treatise on Geophysics (Second Edition) (p. 789-827). Elsevier. doi: 10.1016/B978-0-444-53802-4.00021-X

Rondenay, S. (2009). Upper Mantle Imaging with Array Recordings of Converted and Scattered Teleseismic Waves. Surv. Geophys., 30, 377-405. doi: 10.1007/ s10712-009-9071-5

Roth, J. B., Fouch, M. J., James, D. E., \& Carlson, R. W. (2008). Threedimensional seismic velocity structure of the northwestern United States. Geophys. Res. Lett., 35(L15304). doi: 10.1029/2008GL034669

Rowe, M. C., Peate, D. W., \& Newbrough, A. (2011). Compositional and thermal evolution of olivine-hosted melt inclusions in small-volume basaltic eruptions: a "simple" example from Dotsero Volcano, NW Colorado. Contrib. Mineral. Petrol., 161, 197-211. doi: 10.1007/s00410-010-0526-y

Rychert, C. A., Rondenay, S., \& Fischer, K. M. (2007). P-to-S and S-to-P imaging of a sharp lithosphereasthenosphere boundary beneath eastern North America. J. Geophys. Res., 112(B08314), 1-21. doi: 10.1029/2006JB004619

Rychert, C. A., \& Shearer, P. M. (2009). A Global View of the LithosphereAsthenosphere Boundary. Science, 324(5926), 495-498. doi: 10.1126/ science.1169754

Savage, B., \& Silver, P. G. (2008). Evidence for a compositional boundary within the lithospheric mantle beneath the Kalahari craton from $\mathrm{S}$ receiver functions. Earth Planet. Sci. Lett., 272, 600-609. doi: 10.1016/j.epsl.2008.05.026

Schaeffer, A., \& Lebedev, S. (2014). Imaging the North American continent using waveform inversion of global and USArray data. Earth Planet. Sci. Lett., 402, 26-41. doi: 10.1016/j.epsl.2014.05.014

Schmandt, B., \& Humphreys, E. (2010). Complex subduction and small-scale convection revealed by body-wave tomography of the western United States upper mantle. Earth Planet. Sci. Lett., 297, 435-445. doi: 10.1016/ j.epsl.2010.06.047

Schmandt, B., \& Humphreys, E. (2011). Seismically imaged relict slab from the 55 Ma Siletzia accretion to the northwest United States. Geology, 39(2), 175-178. doi: $10.1130 / \mathrm{G} 31558.1$

Schmandt, B., \& Lin, F.-C. (2014). $\quad$ P and S wave tomography of the mantle beneath the United States. Geophys. Res. Lett., 41, 6342-6349. doi: 10.1002/ 2014GL061231

Schmandt, B., Lin, F.-C., \& Karlstrom, K. E. ～(2015). Distinct crustal isostasy trends east and west of the Rocky Mountain Front. Geophys. Res. Lett., 42, 10290-10298. doi: 10.1002/2015GL066593

Schmidt, M. E., Grunder, A. L., \& Rowe, M. L. (2008). Segmentation of the Cascade Arc as indicated by $\mathrm{Sr}$ and $\mathrm{Nd}$ isotopic variation among diverse primitive basalts. Earth Planet. Sci. Lett., 266(1-2), 166-181. doi: 10.1016/j.epsl.2007.11.013

Schulze, K., Marquardt, H., Kawazoe, T., Ballaran, T. B., McCammon, C., Koch-Müller, M., ... Marquardt, K. (2018). Seismically invisible water in Earth's transition zone? Earth Planet. Sci. Lett., 498, 9-16. doi: 10.1016/j.epsl.2018.06.021

Selway, K., Ford, H., \& Kelemen, P. (2015). The seismic mid-lithosphere discontinuity. Earth Planet. Sci. Lett., 414, 45-57. doi: 10.1016/j.epsl.2014.12.029

Shen, W., \& Ritzwoller, M. H. (2016). Crustal and uppermost mantle structure beneath the United States. J. Geophys. Res.: Solid Earth, 121, 4306-4342. doi: 10.1002/2016JB012887

Shen, X., Kim, Y., Song, T.-R. A., \& Lim, H. (2019). Data-oriented constraint on the interpretation of $\mathrm{S}$ receiver function and its application to observations of seismic discontinuities in the lithosphereasthenosphere system. Geophys. J. Int., 219, 496-513. doi: 10.1093/gji/ggz316 
Sigloch, K. (2011). Mantle provinces under North America from multifrequency P wave tomography. Geochem. Geophys. Geosyst., 12(2), 1-27. doi: 10.1029/ 2010GC003421

Simmons, N. A., Forte, A. M., Boschi, L., \& Grand, S. P. (2010). GyPSuM: A joint tomographic model of mantle density and seismic wave speeds. J. Geophys. Res, 115(B12310). doi: 10.1029/2010JB007631

Smith, E. I., Sánchez, A., Walker, J. D., \& Wang, K. (1999). Geochemistry of Mafic Magmas in the Hurricane Volcanic Field, Utah: Implications for Small and LargeScale Chemical Variability of the Lithospheric Mantle. J. Geol., 107(4), 433-448. doi: $10.1086 / 314355$

Smyth, J. R. $\quad(1987) . \quad \beta-\mathrm{Mg}_{2} \mathrm{SiO}_{4}$ : A potential host for water in the mantle? Am. Mineral., 72, 1051-1055.

Sodoudi, F., Yuan, X., Kind, R., Lebedev, S., Adam, J. M. C., Kästle, E., \& Tilmann, F. (2013). Seismic evidence for stratification in composition and anisotropic fabric within the thick lithosphere of Kalahari Craton. Geochem. Geopyhs. Geosyst., 14, 5393-5412. doi: 10.1002/2013GC004955

Sodoudi, F., Yuan, X., Liu, Q., Kind, R., \& Chen, J. (2006). Lithospheric thickness beneath the Dabie Shan, central eastern China from S receiver functions. Geophys. J. Int., 166, 1363-1367. doi: 10.1111/j.1365-246X.2006.03080.x

Sonder, L. J., \& Jones, C. H. (1999). Western United States Extension: How the West was Widened. Annu. Rev. Earth Planet., 27(1), 417-462. doi: 10.1146/ annurev.earth.27.1.417

Song, T.-R. A., Helmberger, D. V., \& Grand, S. P. (2004). Low-velocity zone atop the 410-km seismic discontinuity in the northwestern United States. Nature, 427, 530-533. doi: 10.1038/nature02231

Spetzler, J., \& Snieder, R. (2004). The Fresnel volume and transmitted waves. Geophysics, 69(3), 653-663. doi: 10.1190/1.1759451

Stein, S., Stein, C. A., Elling, R., Kley, J., Keller, G. R., Wysession, M., ... Moucha, R. (2015). Insights from North America's failed Midcontinent Rift into the evolution of continental rifts and passive continental margins. Tectonophysics, 744, 403-421. doi: 10.1016/j.tecto.2018.07.021

Stern, T. A., Henrys, S. A., Okaya, D., Louie, M. K., Savage, S., Lamb, H., ... Iwasaki, T. (2015). A seismic reflection image for the base of a tectonic plate. Nature, 518, 85-88. doi: 10.1038/nature14146

Stixrude, L., \& Lithgow-Bertelloni, C. (2005). Thermodynamics of mantle minerals - I. Physical properties. Geophys. J. Int., 162(2), 610-632. doi: 10.1111/j.1365 $-246 X .2005 .02642 . \mathrm{x}$

Stixrude, L., \& Lithgow-Bertelloni, C. (2011). Thermodynamics of mantle minerals - II. Phase equilibria. Geophys. J. Int., 184(3), 1180-1213. doi: 10.1111/j.1365 $-246 \mathrm{X} .2010 .04890 . \mathrm{x}$

Sundberg, M., \& Cooper, R. (2010). A composite viscoelastic model for incorporating grain boundary sliding and transient diffusion creep; correlating creep and attenuation responses for materials with a fine grain size. Philos. Mag., 90(20), 2817-2840. doi: 10.1080/14786431003746656

Sweetkind, D. S., Rytuba, J. J., Langenheim, V. E., \& Fleck, R. J. (2011). Geology and geochemistry of volcanic centers within the eastern half of the Sonoma volcanic field, northern San Francisco Bay region, California. Geosphere, 7(3), 629-657. doi: 10.1130/GES00625.1

Tackley, P. J., Xie, S., Nakagawa, T., \& Hernlund, J. W. (2005). Numerical and laboratory studies of mantle convection: Philosophy, accomplishments, and thermochemical structure and evolution. In R. D. van der Hilst, J. D. Bass, J. Matas, \& J. Trampert (Eds.), Earth's Deep Mantle: Structure, Composition, and Evolution. Washington, DC: American Geophysical Union. doi: 10.1029/160GM07

Tan, Y., \& Helmberger, D. V. (2007). Trans-Pacific upper mantle shear velocity 
structure. J. Geophys. Res., 112(B08301), 1-20. doi: 10.1029/2006JB004853

Tauzin, B., Debayle, E., \& Wittlinger, G. (2008). The mantle transition zone as seen by global Pds phases: No clear evidence for a thin transition zone beneath hotspots. J. Geophys. Res., 113(B08309), 1-17. doi: 10.1029/2007JB005364

Tauzin, B., Debayle, E., \& Wittlinger, G. (2010). Seismic evidence for a global lowvelocity layer within the Earth's upper mantle. Nat. Geosci., 3, 718721. doi: 10.1038/ngeo969

Tauzin, B., Kim, S., \& Kennett, B. L. N. (2017). Pervasive seismic lowvelocity zones within stagnant plates in the mantle transition zone: Thermal or compositional origin? Earth Planet. Sci. Lett., 477, 1-13. doi: 10.1016/j.epsl.2017.08.006

Tauzin, B., van der Hilst, R. D., Wittlinger, G., \& Ricard, Y. $\quad$ (2013). Multiple transition zone seismic discontinuities and low velocity layers below western United States. J. Geophys. Res.: Solid Earth, 118, 2307-2322. doi: $10.1002 /$ jgrb.50182

Thio, V., Cobden, L., \& Trampert, J. (2015). Seismic signature of a hydrous mantle transition zone. Phys. Earth Planet. Inter., 250, 46-63. doi: 10.1016/j.pepi .2015 .11 .005

Toffelmier, D. A., \& Tyburczy, J. A. (2007). Electromagnetic detection of a 410-kmdeep melt layer in the southwestern United States. Nature, 447, 991-994. doi: 10.1038 /nature 05922

van der Lee, S., \& Frederiksen, A. (2005). Surface Wave tomography applied to the North American upper mantle. In A. Levander \& G. Nolet (Eds.), Seismic Earth: Array Analysis of Broadband Seismograms. doi: 10.1029/157GM05

van der Lee, S., \& Nolet, G. (1997). Seismic image of the subducted trailing fragments of the Farallon plate. $\quad$ Nature, 386(6622), 266-269. doi: $10.1038 / 386266 \mathrm{a} 0$

Vinnik, L., \& Farra, V. (2007). Low S velocity atop the 410-km discontinuity and mantle plumes. Earth Planet. Sci. Lett., 262, 398-412. doi: 10.1016/j.epsl.2007 .07 .051

Vinnik, L., Ren, Y., Stutzmann, E., Farra, V., \& Kiselev, S. (2010). Observations of S410p and S350p phases at seismograph stations in California. J. Geophys. Res., 115(B05303), 1-12. doi: 10.1029/2009JB006582

Vinnik, L. P. (1977). Detection of waves converted from P to SV in the mantle. Phys. Earth Planet. Inter., 15(1), 39-45. doi: 10.1016/0031-9201(77)90008-5

Vinnik, L. P., Foulger, G. R., \& Du, Z. (2005). Seismic boundaries in the mantle beneath Iceland: a new constraint on temperature. Geophys. J. Int., 160, 533538. doi: 10.1111/j.1365-246X.2005.02529.x

Wang, K., Plank, T., Walker, J. D., \& Smith, E. I. (2002). A mantle melting profile across the Basin and Range, SW USA. J. Geophys. Res., 107(B1). doi: 10 .1029/2001JB000209

Watt, J. P., Davies, G. F., \& O'Connell, R. J. (1976). The elastic properties of composite materials. Rev. Geophys., 14(4), 541-563. doi: 10.1029/ RG014i004p00541

Weidner, D. J., \& Wang, Y. (1998). Chemical- and Clapeyron-induced buoyancy at the $660 \mathrm{~km}$ discontinuity. J. Geophys. Res., 103(B4), 7431-7441. doi: 10.1029/ 97JB03511

Wenrich, K. J., Billingsley, G. H., \& Blackerby, B. A. (1995). Spatial migration and compositional changes of Miocene-Quaternary magmatism in the Western Grand Canyon. J. Geophys. Res., 100(B6), 10417-10440. doi: 10.1029/95JB00373

Whitmeyer, S. J., \& Karlstrom, K. E. (2007). Tectonic model for the Proterozoic growth of North America. Geosphere, 3, 220-259. doi: 10.1029/2012JB009639

Williams, H., Hoffman, P. F., Lewry, J. F., Monger, J. W. H., \& Rivers, T. (1991). Anatomy of North America: thematic geologic portrayals of the continent. 
Tectonophysics, 187(1-3), 117-134. doi: 10.1016/0040-1951(91)90416-P

Wilson, D. C., Angus, D. A., Ni, J. F., \& Grand, S. P. (2006). Constraints on the interpretation of S-to-P receiver functions. Geophys. J. Int., 165, 969-980. doi: 10.1111/j.1365-246X.2006.02981.x

Wölbern, I., Rümpker, G., Link, K., \& Sodoudi, F. (2012). Melt infiltration of the lower lithosphere beneath the Tanzania craton and the Albertine rift inferred from S receiver functions. Geochem. Geophys. Geosyst., 13(8), 1-20. doi: 10.1029/2012GC004167

Wood, B. J., \& Holloway, J. R. (1984). A thermodynamic model for subsolidus equilibria in the system CaOMgOAl2O3SiO2. Geochim. Cosmochim. Acta, 48(1), 159-176. doi: 10.1016/0016-7037(84)90358-2

Xiao, J., Hier-Majumder, S., Tauzin, B., \& Waltham, D. (2020). An inversion approach for analysing the physical properties of a seismic low-velocity layer in the upper mantle. Phys. Earth Planet. Inter., 304(106502). doi: 10.1016/j.pepi.2020.106502

Xu, W., Lithgow-Bertelloni, C., Stixrude, L., \& Ritsema, J. (2008). The effect of bulk composition and temperature on mantle seismic structure. Earth Planet. Sci. Lett., 275, 70-79. doi: 10.1016/j.epsl.2008.08.012

Yogodzinski, G. M., Naumann, T. R., Smith, E. I., \& Bradshaw, T. K. Evolution of a mafic volcanic field in the central Great basin, south Central Nevada. J. Geophys. Res., 101 (B8), 17425-17445. doi: 10.1029/96JB00816

Yuan, H., French, S., Cupillard, P., \& Romanowicz, B. (2014). Lithospheric expression of geological units in central and eastern North America from full waveform tomography. Earth Planet. Sci. Lett., 402, 176-186. doi: 10.1016/j.epsl.2013.11.057

Yuan, H., \& Romanovicz, B. (2010). Lithospheric layering in the North American craton. Nature, 466(7310), 1063-1068. doi: 10.1038/nature09332

Yuan, H., Romanowicz, B., Fischer, K. M., \& Abt, D. (2011). 3-D shear wave radially and azimuthally anisotropic velocity model of the North American upper mantle. Geophys. J. Int., 184(3), 1237-1260. doi: 10.1111/ j.1365-246X.2010.04901.x

Yuan, X., Kind, R., Li, X., \& Wang, R. (2006). The S receiver functions: synthetics and data example. Geophys. J. Int., 165, 555-564. doi: 10.1111/j.1365-246X .2006.02885.x

Zhang, Q., Sandvol, E., \& Liu, M. (2009). Lithospheric velocity structure of the New Madrid Seismic Zone: A joint teleseismic and local P tomographic study. Geophys. Res. Lett., 36(L11305). doi: 10.1029/2009GL037687 

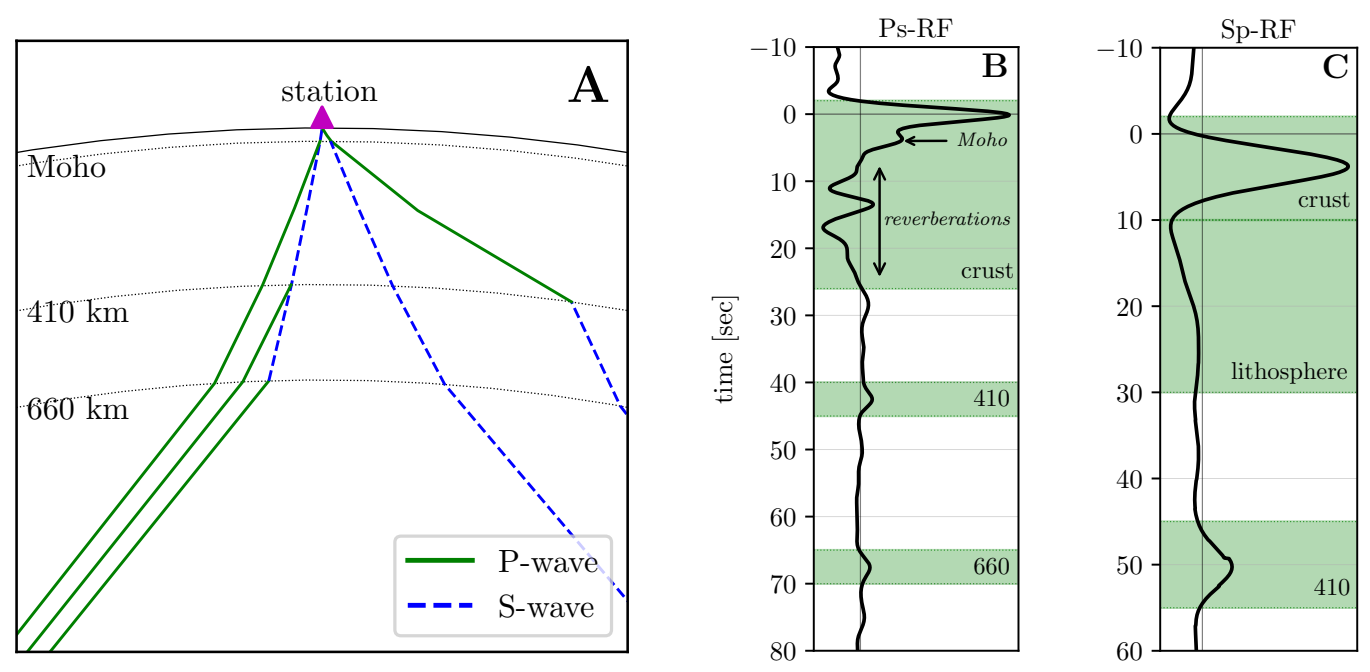

Figure 1. Illustration of conversions of body waves at the Moho and the 410- and 660-km seismic discontinuities in the Earth (A) and corresponding synthetic P-to-s (B) and S-to-p receiver functions (C) based on the seismic reference model IASP91 (Kennett \& Engdahl, 1991). $\mathrm{P}$ - and S-waves are shown as green (solid) and blue (dashed) lines, respectively. Time windows including arrivals of converted waves are shaded in green. Note that the polarity and time axis of Sp RFs are flipped as a result of which arrivals with positive travel times arrive prior to the $\mathrm{S}$-wave and are not masked by crustal reverberations as is the case for P-to-s conversions 

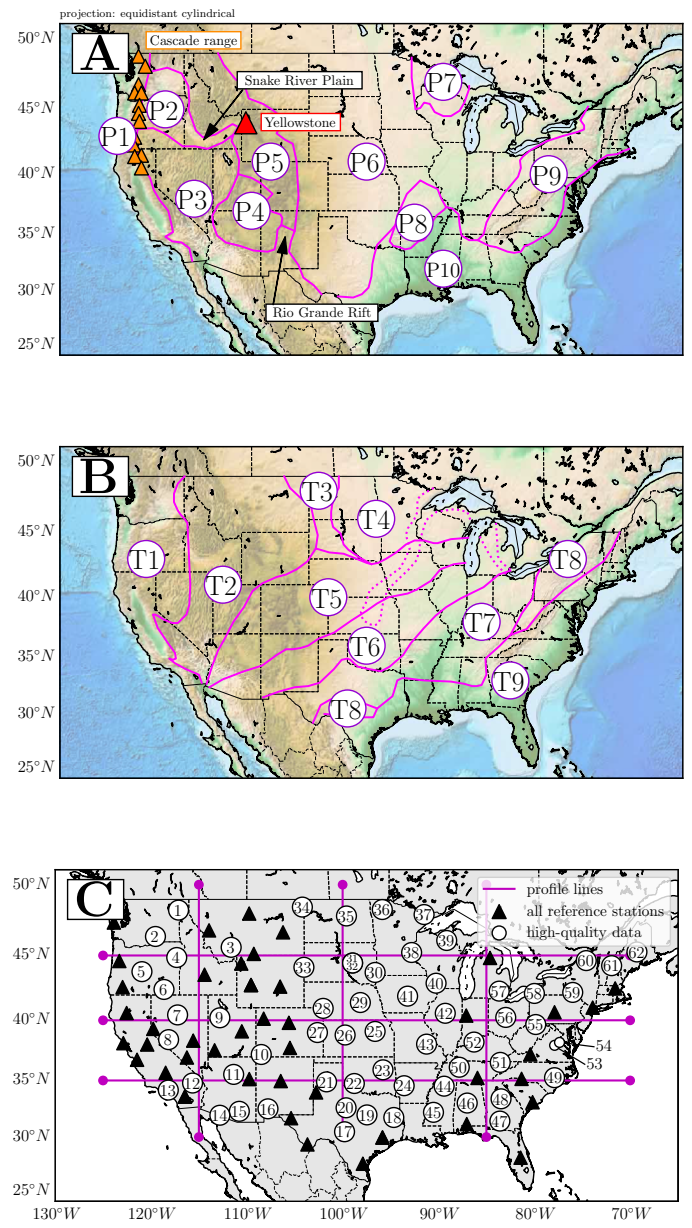

Figure 2. Main physiographic features (Fenneman, 1928) of the contiguous USA (A): P1: Pacific mountain system (incl. Cascade Range); P2: Columbia plateau (incl. Snake River Plain and Yellowstone Hotspot); P3: Basin and Range (incl. Rio Grande Rift); P4: Colorado plateau; P5: Rocky mountain system; P6: Interior Highlands; P7: Laurentian Highlands; P8: Interior Highlands; P9: Appalachian Highlands; P10: Atlantic Plain. The tectonic provinces (Hoffman, 1988; Whitmeyer \& Karlstrom, 2007) represent the long-term geological history of the continent B: the oldest parts of the continent, i.e., of precambrian age, include the Greater Wyoming province (T2) and Superior craton (T4), which are connected along the Trans-Hudson orogen (T3). Proterozoic orogenies accreted the Yavapai (T5), Mazatzal (T6), Granite-Rhyolite (T7), and Grenville provinces (T8) to the cratonic core. During episodes of extension in proterozoic times, the mid-continental rift was formed but abandoned, and later the Pacific and paleo-Atlantic oceans were opened. The closure of the latter during the paleozoic formed the Appalachian mountain belt (T9, P9), which, nowadays, is bordered by the Atlantic plains (P10), i.e., the relatively young passive continental margin, to the east and south. In contrast to the east, the western margin (T1) is dominated by subduction processes acting since the mesozoic (e.g., Sonder \& Jones, 1999; Dickinson, 2004; Humphreys, 2009), which have resulted in accretion of terrane to the American continent, volcanism (Cascade range, P1), and extensional tectonics (Basin and Range, P3). The topography model underlying the maps is that of ETOPO1 (Amante \& Eakins, 2009). C: location of USArray reference stations (www.usarray.org). White circles indicate stations, where either P-to-s or S-to-p receiver functions or both were inverted, while black triangles represent stations for which data were processed but because of quality constraints were not considered in the inversion. Station numbering and details are given in Table S.1. Magenta lines indicate profiles along which cross sections of mantle seismic properties are shown 

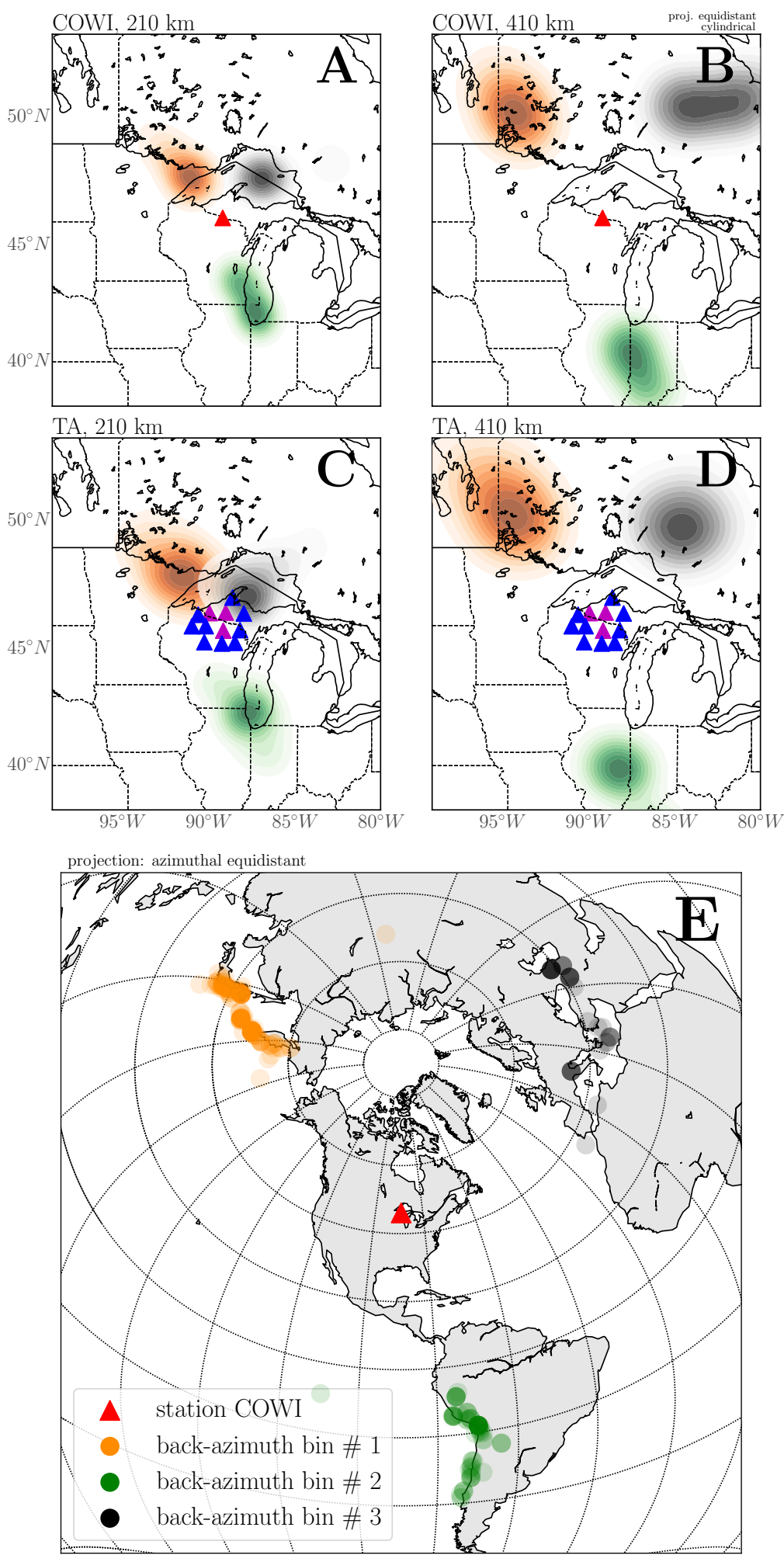

Figure 3. A-D: normalized Fresnel-zone weights of S-to-p piercing points (color coded by back-azimuth; see panel $\mathbf{E})$ at a depth of $210 \mathrm{~km}(\mathbf{A}$ and $\mathbf{C})$ and $410 \mathrm{~km}(\mathbf{B}$ and $\mathbf{D})$ for the events recorded at 39-COWI (red triangle) and 12 near-by transportable USArray stations within a distance of $\sim 70 \mathrm{~km}$ (TA1; magenta triangles) and $\sim 140 \mathrm{~km}$ (TA2; blue triangles), respectively. E: location of station 39-COWI and the seismic events used for computing S-to-p receiver functions coloured by back-azimuth (dots) 

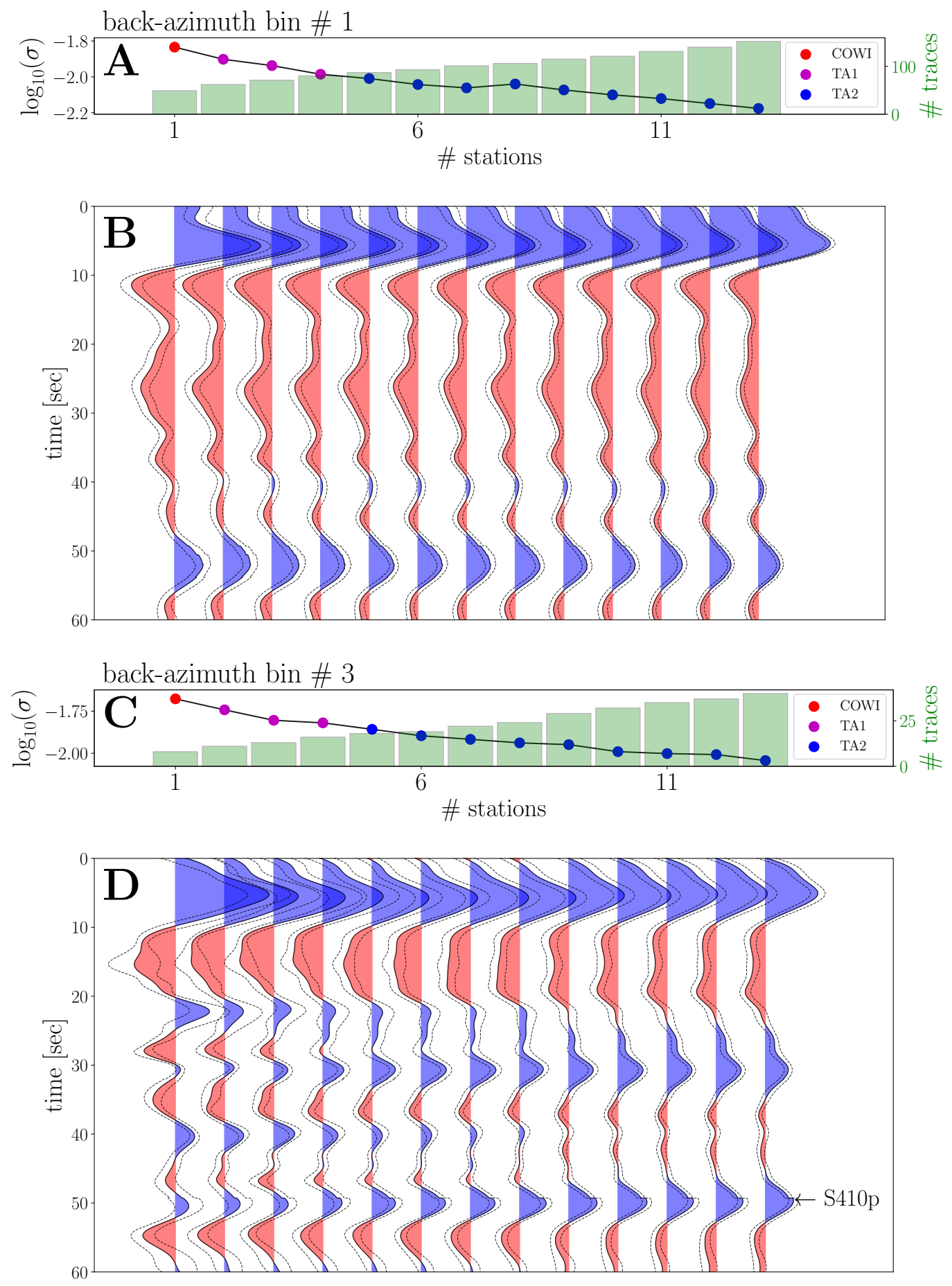

Figure 4. S-to-p receiver function stacks, mean uncertainty $(\sigma)$, and number of summed traces (green bars) for two distinct back-azimuth bins related to events in the west Pacific (\#1; $\mathbf{A}$ and $\mathbf{B}$ ) and Europe (\#3; $\mathbf{C}$ and $\mathbf{D})$, respectively. Including data recorded at transportable stations (blue and magenta dots) (TA1 and TA2, respectively) of the reference station (39COWI, red dot) reduces uncertainty and enhances the S410p phase in back-azimuth bin \# 3 (D) 
Ps-RF, 5s

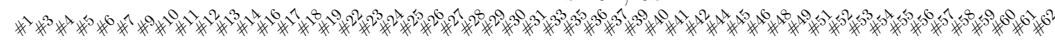

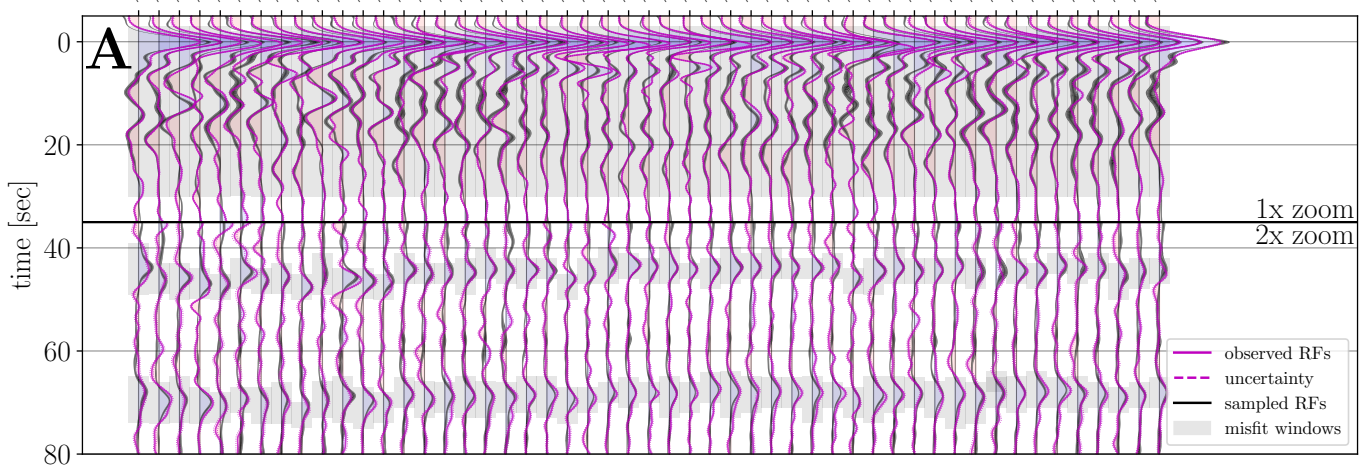

Sp-RF, 10s

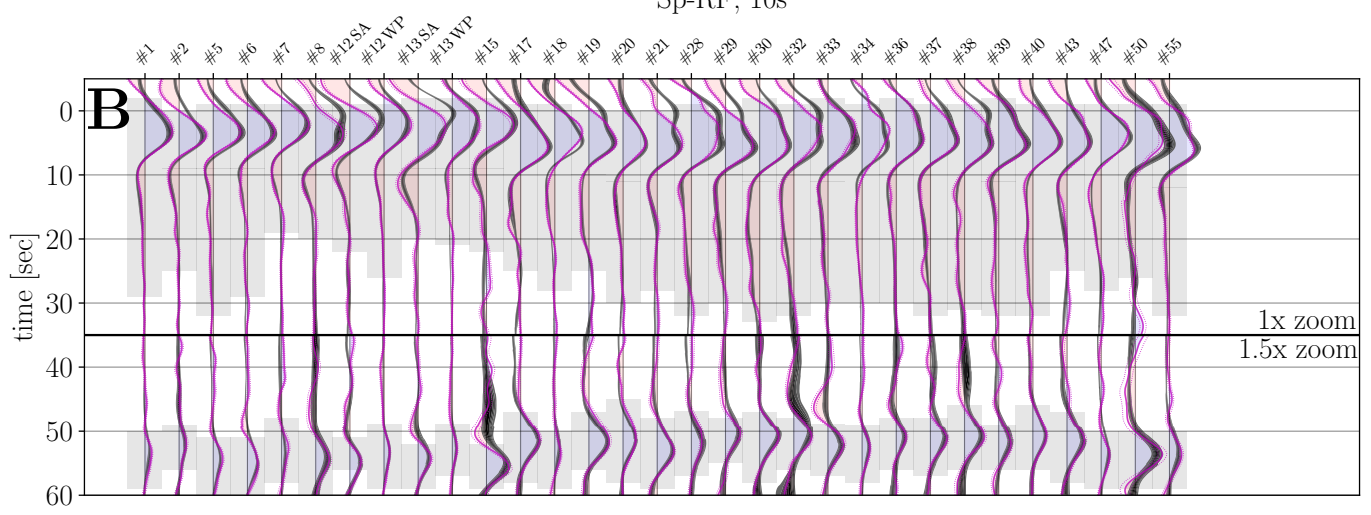

Figure 5. Data misfit between inverted and observed high-quality P-to-s ( $5 \mathrm{~s}$ low-pass period, A) and S-to-p receiver functions (10 s low-pass period, B). Observations and uncertainties are shown as magenta lines, sampled receiver functions as contours (dark bands), and misfit windows in light gray. Station numbering is shown in Figure 2C, whereas 'SA' and 'WP' denote events located in South America and the West Pacific, respectively. For improved visibility, amplitudes of conversions from the 410- and 660-km seismic discontinuities have been scaled up. Equivalent data fits for P-to-s and S-to-p receiver functions at low-pass periods of 8,10 , and $15 \mathrm{~s}$ are shown in supplementary Figure S.19 

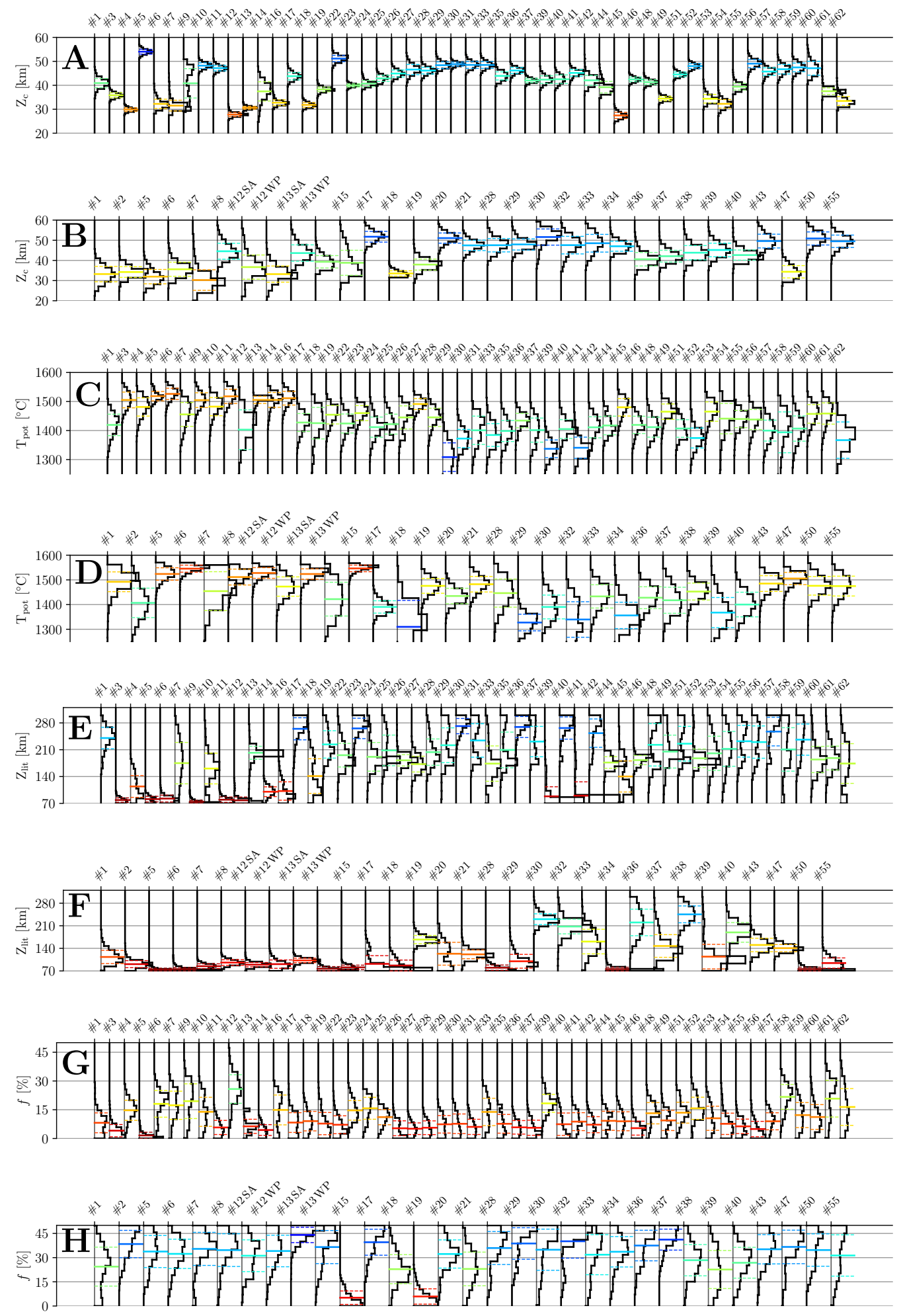

Figure 6. Sampled marginal posterior probability distributions (black lines) of crustal thickness, $\mathrm{Z}_{\mathrm{c}}(\mathbf{A}, \mathbf{B})$, potential temperature, $\mathrm{T}_{\text {pot }}(\mathbf{C}, \mathbf{D})$, lithosphere thickness, $\mathrm{Z}_{\text {lit }}(\mathbf{E}, \mathbf{F})$, and basalt fraction, $f(\mathbf{G}, \mathbf{H})$ from inversion of $\mathrm{P}$-to-s and S-to-p receiver functions, respectively. Mean values and standard deviations of the distributions are shown as thick and thin lines, respectively, where choice of color is based on the colormaps used in Figures 7 and 9. Station numbering refers to Figure $2 \mathrm{C}$, whereas 'SA' and 'WP' refer to events from South America and the West Pacific, respectively 

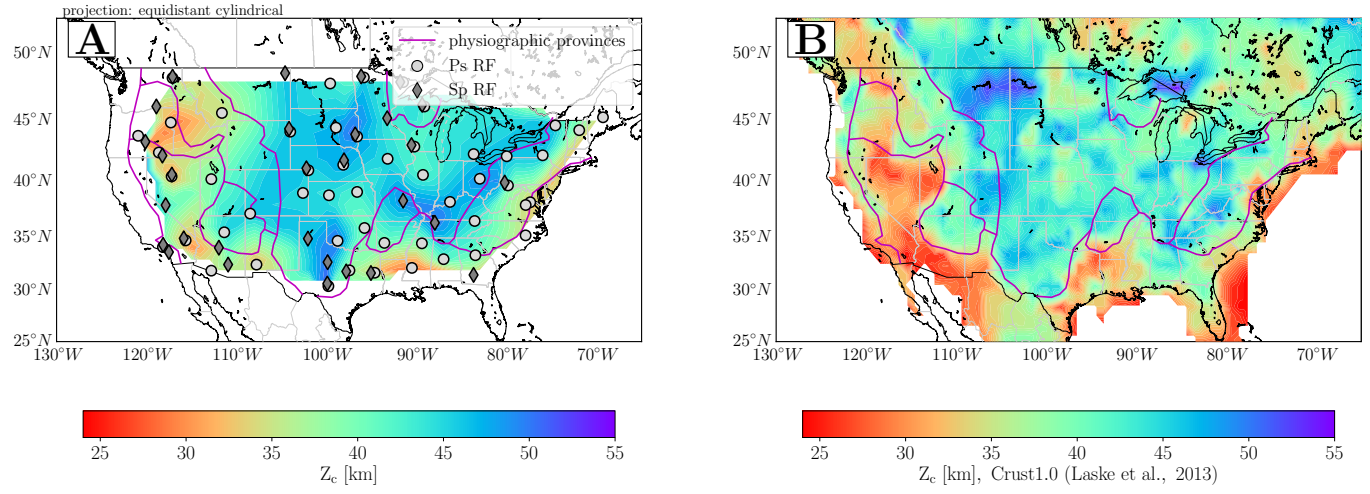

Figure 7. A: Mean crustal thickness, $\mathrm{Z}_{\mathrm{c}}$, across the contiguous USA interpolated from migrated P-to-s (circles) and S-to-p (diamonds) receiver functions. B: Crustal thickness map from model Crust1.0 (Laske et al., 2013). Physiographic provinces are outlined in magenta (Fenneman, 1928, cf. Figure 2A)
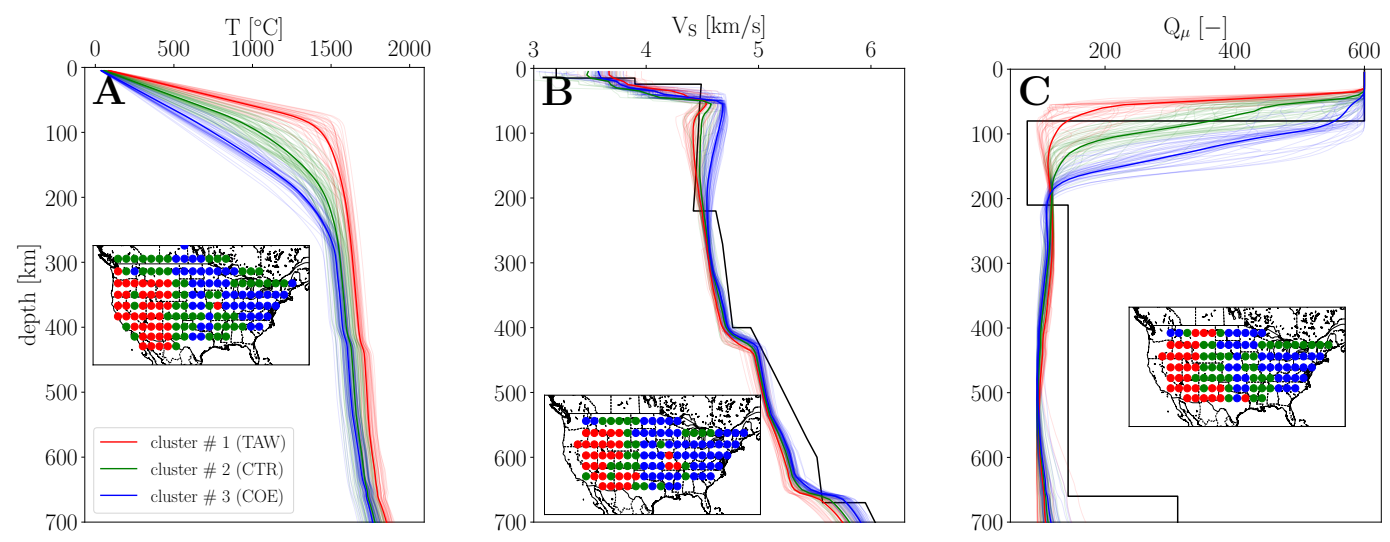

Figure 8. Profiles of temperature (T, A), S-wave velocity $\left(\mathrm{V}_{\mathrm{S}}, \mathbf{B}\right)$, and shear attenuation profiles $\left(\mathrm{Q}_{\mu}, \mathbf{C}\right)$ obtained from inversion of P-to-s and S-to-p receiver functions and clustering analysis. Profiles are clustered into three clusters according to similarity (color-coded) and displayed in light color, whereas the mean profile of each cluster is shown as a thick line. The tectonic regions identified in panel $\mathbf{A}$ will be referred to as tectonically active West (red; TAW), central transition regions (green; CTR), and cratonic-orogenic East (blue; COE) in the following. The maps shown in the insets are interpolated from the inversion results on a $2.5^{\circ} \times 2.5^{\circ}$-grid. PREM profiles are shown in black in panels $(\mathbf{B})$ and $(\mathbf{C})$ 

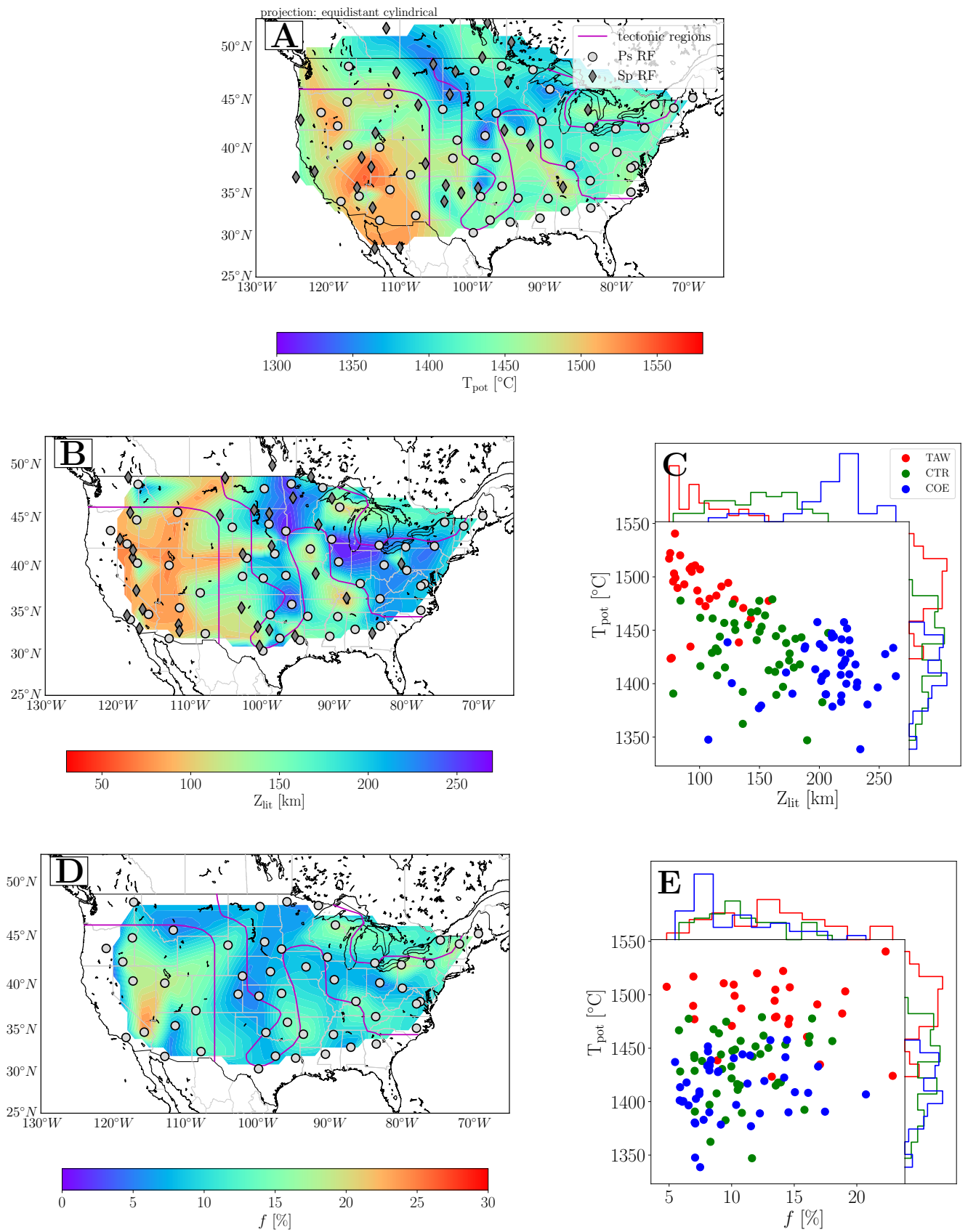

Figure 9. Models of the North American thermo-chemical mantle structure: potential temperature, $\mathrm{T}_{\text {pot }}(\mathbf{A})$, lithosphere thickness, $\mathrm{Z}_{\text {lit }}(\mathbf{B})$, and basalt fraction, $f(\mathbf{D})$. Tectonic regions identified earlier (cf. Figure 8A) are outlined in magenta. The distribution and correlation of $\mathrm{T}_{\text {pot }}$ with $\mathrm{Z}_{\text {lit }}$ and $f$ for each of these tectonic regions (color coded) are shown in panels $\mathbf{C}$ and E, respectively. Maps derive from P-to-s (circles) and S-to-p (diamonds) receiver functions, respectively, except the compositional map showing basalt fraction (D), where S-to-p receiver function estimates are excluded because of the large uncertainties (see section 6.6). Differences in lateral extent of these maps arise from the migration of S-to-p receiver function results along the converted raypath to different depths (see section 5.4) 

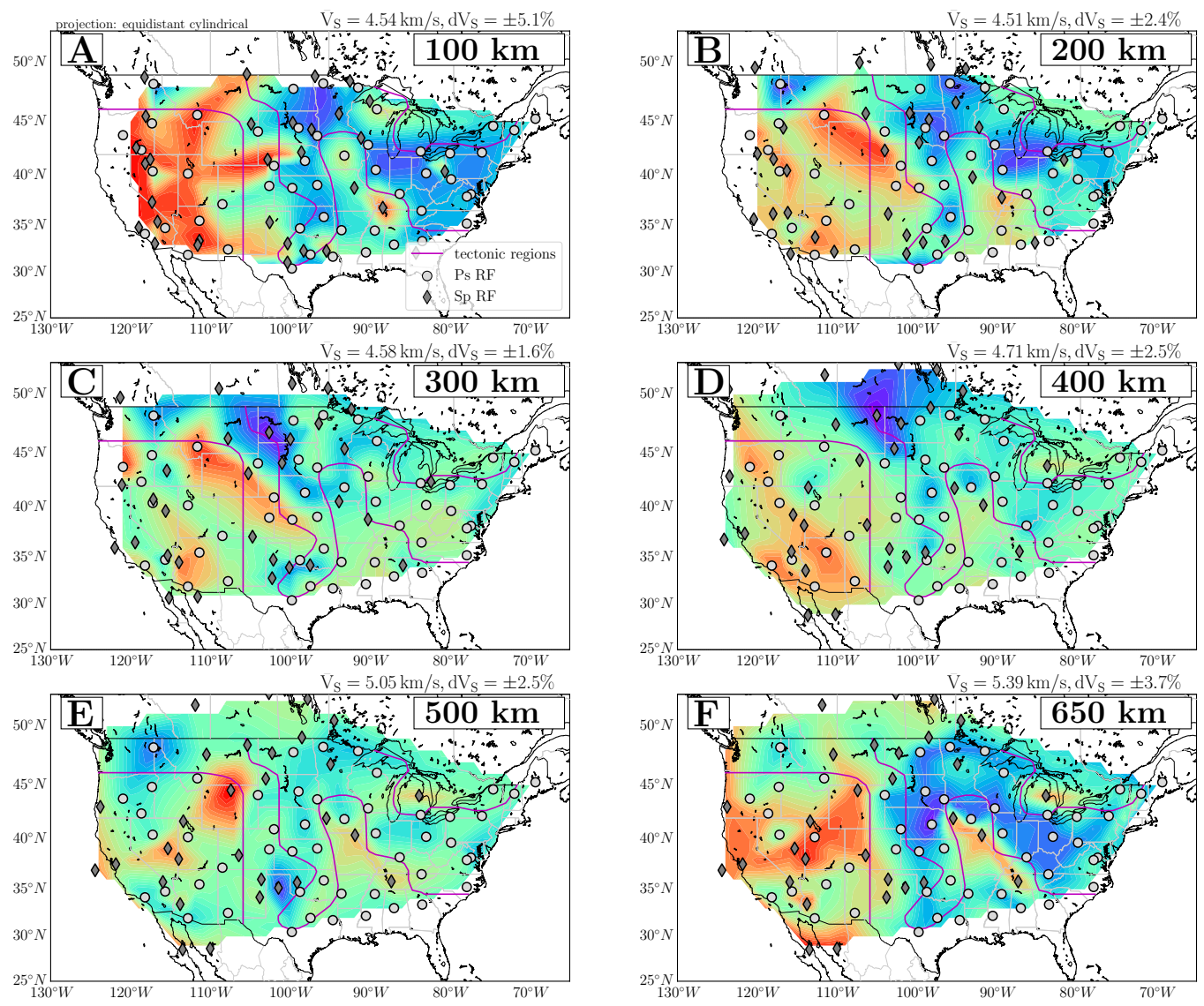

$\mathrm{dV}_{\mathrm{S}}[\%]$

Figure 10. Interpolated $\mathrm{S}$-wave velocity perturbations, $d V_{\mathrm{S}}$, along horizontal slices between 100-650 km depth. All maps share the same colormap but differ in absolute mean velocity and standard deviation (indicated on the top right of each panel). Earlier identified tectonic regions (cf. Figure 8A) are outlined in magenta. Differences in lateral extent of these maps arise from the migration of S-to-p receiver function results along the converted raypath to different depths (see section 5.4) 

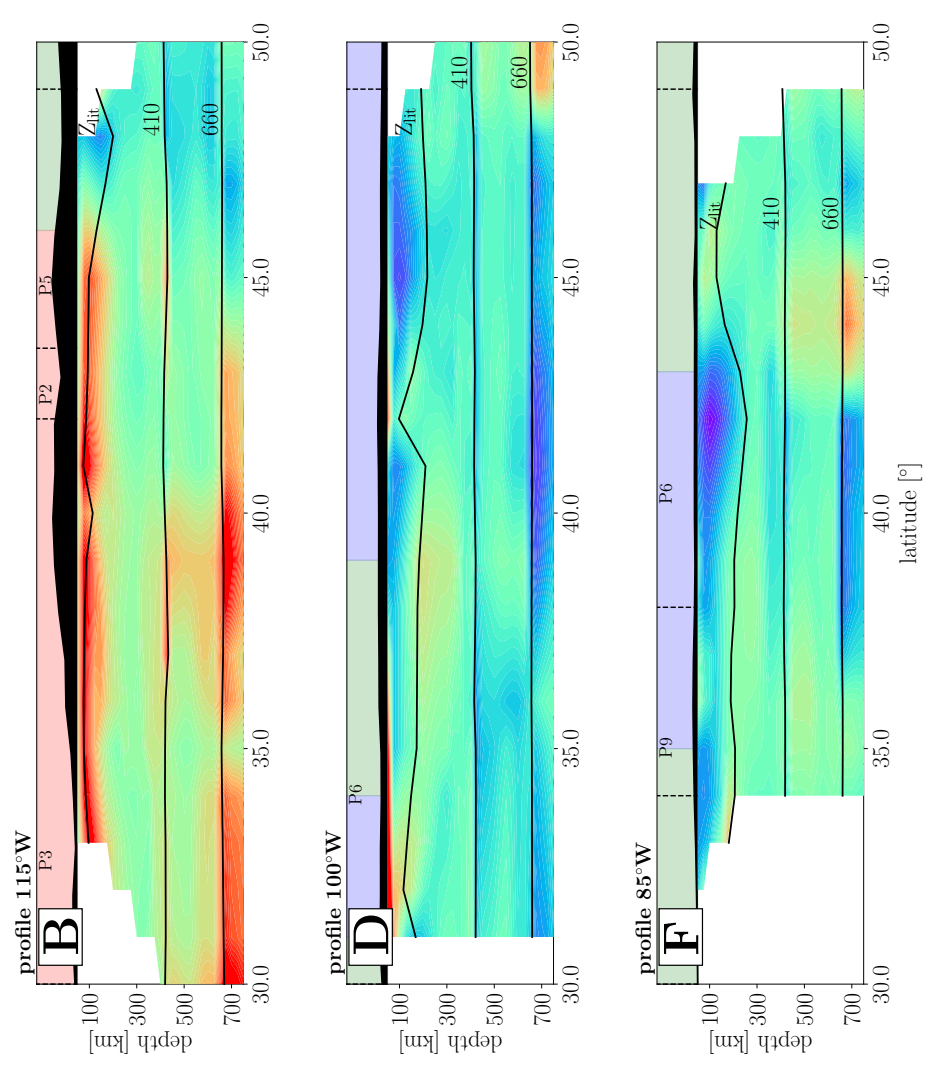

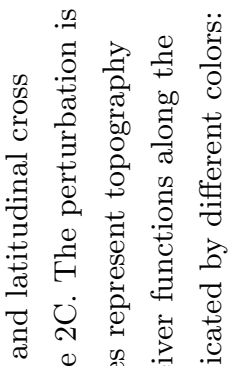

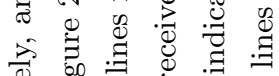

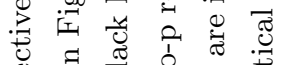

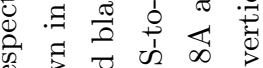

论

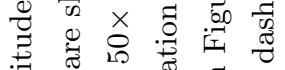

营

乙

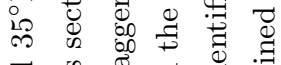

चี

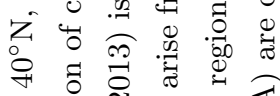

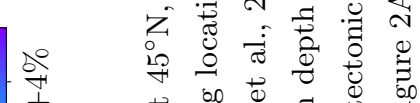

$+\quad \forall$ 年

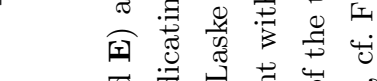

হ च च

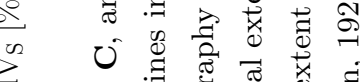

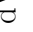
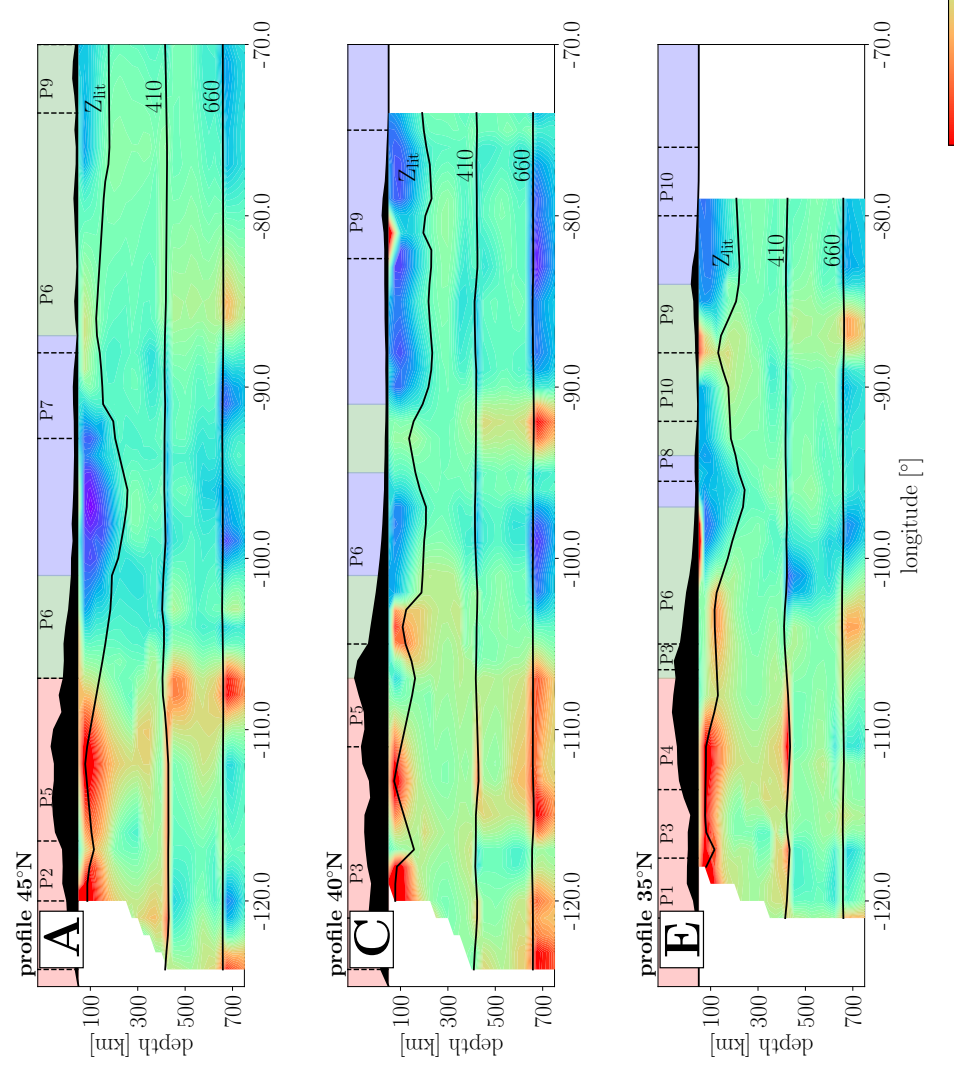

«

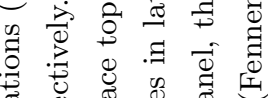

然

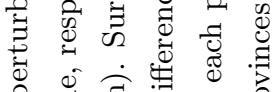

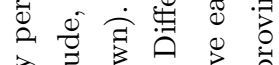

莺营

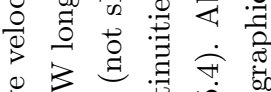

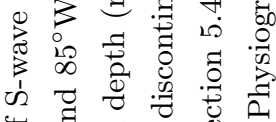

पे สี .

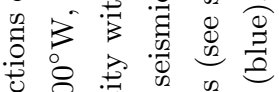

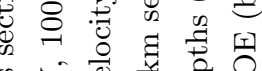

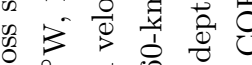

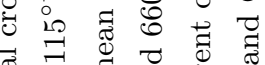

ฮี

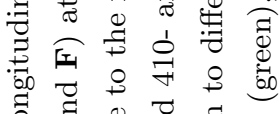

๑

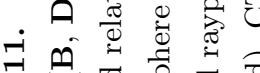

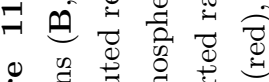

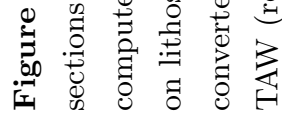



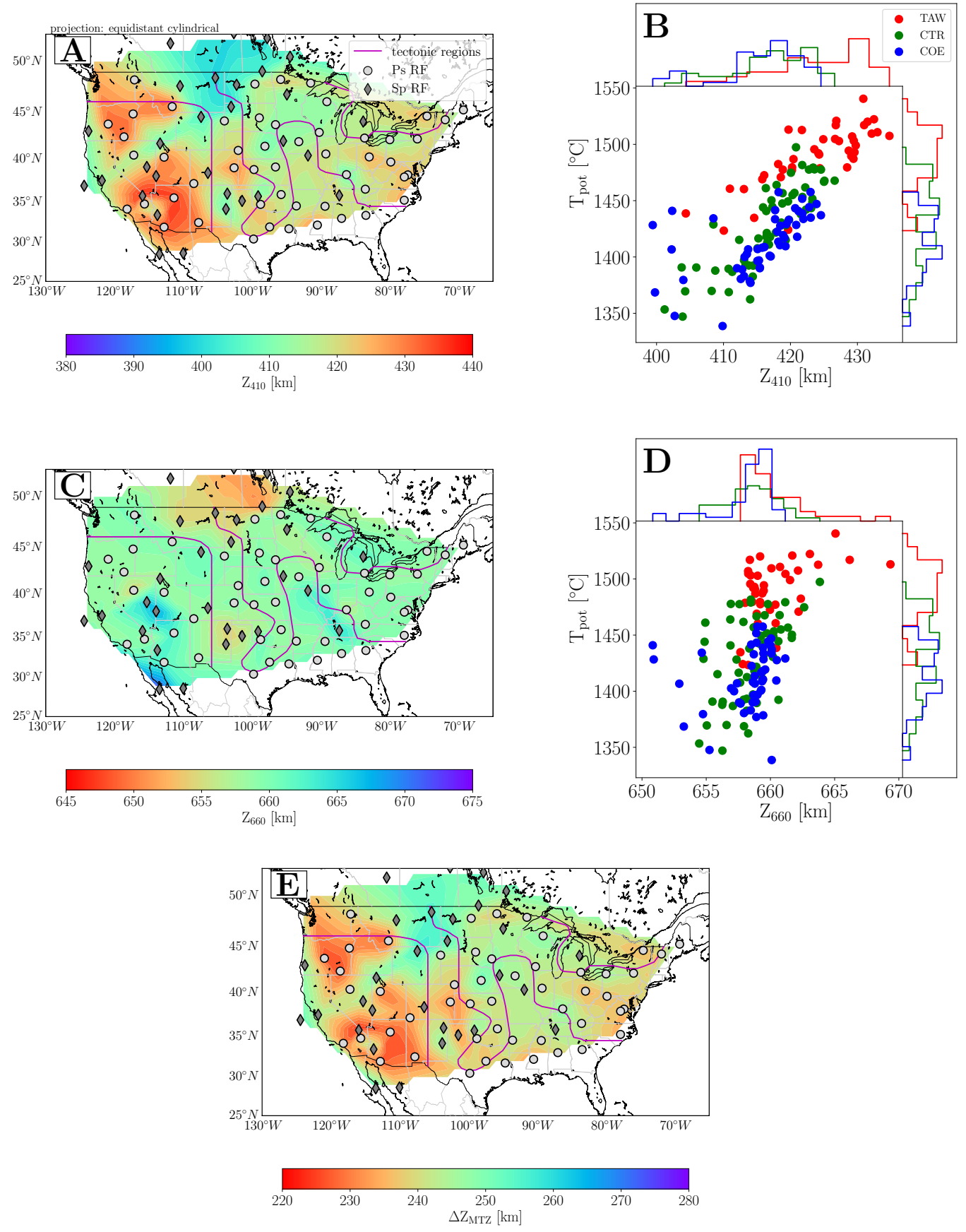

Figure 12. Interpolated maps of mean depth to the major mantle seismic discontinuities at 410 and $660 \mathrm{~km}$ depth, $\mathrm{Z}_{410}(\mathbf{A}), \mathrm{Z}_{660}(\mathbf{C})$, and mantle transition zone thickness, $\Delta \mathrm{Z}_{\mathrm{MTZ}}(\mathbf{E})$. Tectonic regions identified in Figure $8 \mathrm{~A}$ are outlined in magenta. The distribution and correlation of mantle potential temperature $\mathrm{T}_{\text {pot }}$ with $\mathrm{Z}_{410}$ and $\mathrm{Z}_{660}$ for each of these regions (color coded) is shown in panels $\mathbf{B}$ and $\mathbf{D}$, respectively 

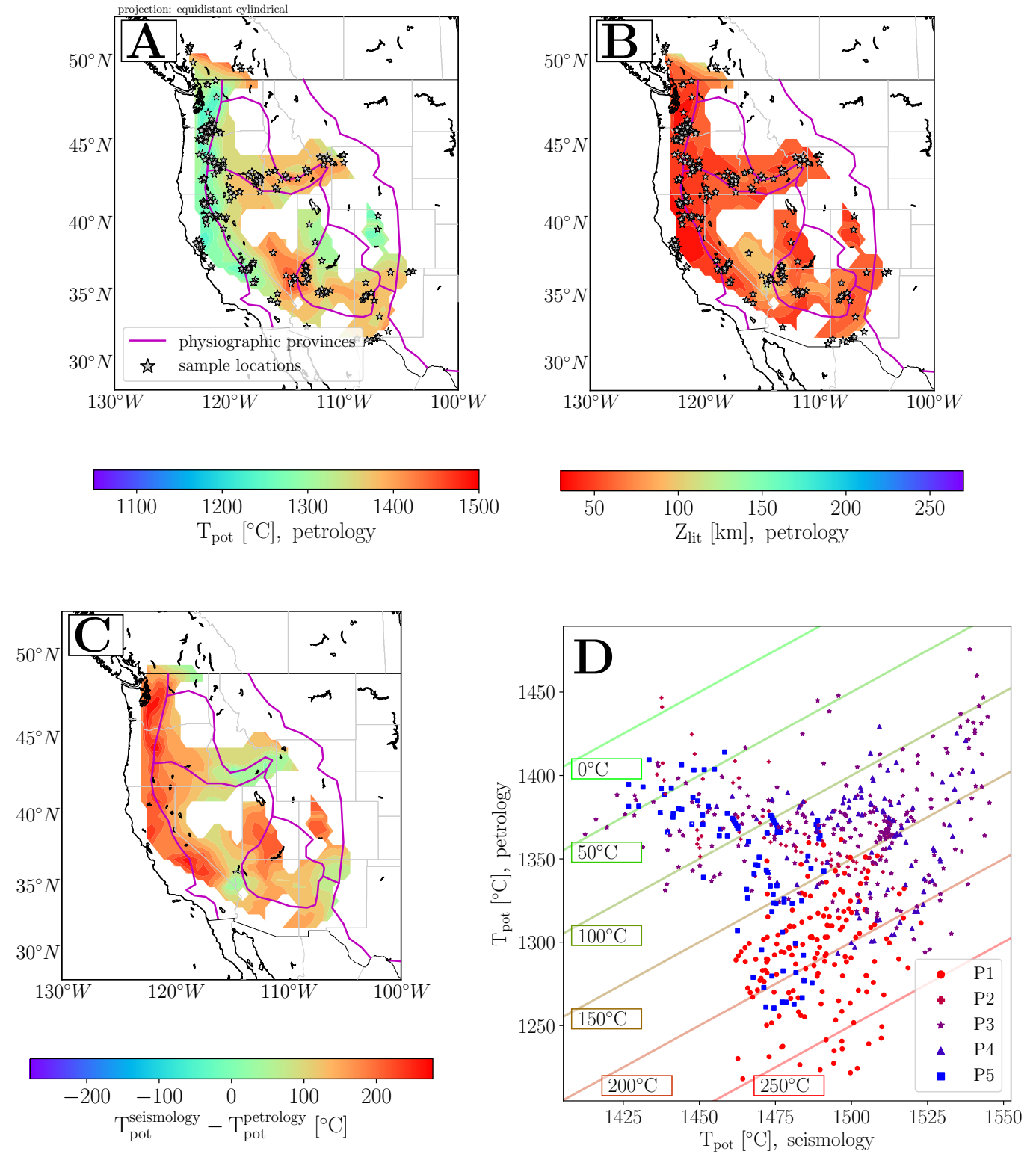

Figure 13. Thermo-chemical structure of the lithosphere underneath the western USA as estimated from thermobarometry: interpolated potential temperature $\left(\mathrm{T}_{\text {pot }}, \mathbf{A}\right)$ and lithosphere thickness $\left(\mathrm{Z}_{\mathrm{lit}}, \mathbf{B}\right)$. The deviation to seismically derived temperature estimates (cf. Figure 9A) is shown in panel C. Cells of the interpolation grid farther away than $1.5^{\circ}$ from the nearest sample location (stars) are masked. Physiographic provinces are outlined in magenta (Fenneman, 1928, cf. Figure 2A). Panel D compares the petrologically and seismically derived temperature estimates (markers colored by physiographic province). Isotherms represent absolute temperature differences, i.e., $\mathrm{T}_{\text {pot }}$ (seismology) $-\mathrm{T}_{\text {pot }}$ (petrology) (color coded and labeled) 